NBER WORKING PAPER SERIES

\title{
DETERMINANTS OF BUSINESS CYCLE COMOVEMENT: A ROBUST ANALYSIS
}

\author{
Marianne Baxter \\ Michael Kouparitsas \\ Working Paper 10725 \\ http://www.nber.org/papers/w10725
}

\begin{abstract}
NATIONAL BUREAU OF ECONOMIC RESEARCH 1050 Massachusetts Avenue Cambridge, MA 02138
\end{abstract}

August 2004

The views expressed herein are those of the authors and not necessarily those of the Federal Reserve Bank of Chicago or the Federal Reserve System. We thank Carrie Jankowski and Faisal Ahmed for excellent research assistance. We thank an anonymous referee, Dan Aaronson, Eric French, Ayhan Kose and Dan Sullivan for helpful comments and suggestions. All errors are our own. The views expressed herein are those of the author(s) and not necessarily those of the National Bureau of Economic Research.

(C2004 by Marianne Baxter and Michael Kouparitsas. All rights reserved. Short sections of text, not to exceed two paragraphs, may be quoted without explicit permission provided that full credit, including (C) notice, is given to the source. 
Determinants of Business Cycle Comovement: A Robust Analysis

Marianne Baxter and Michael Kouparitsas

NBER Working Paper No. 10725

August 2004

JEL No. F33, F41

\section{$\underline{\text { ABSTRACT }}$}

This paper investigates the determinants of business cycle comovement between countries. Our dataset includes over 100 countries, both developed and developing. We search for variables that are "robust" in explaining comovement, using the approach of Leamer (1983). Variables considered are (i) bilateral trade between countries; (ii) total trade in each country; (iii) sectoral structure; (iv) similarity in export and import baskets; (v) factor endowments; and (vi) gravity variables. We find that bilateral trade is robust. However, two variables that the literature has argued are important for business cycles - industrial structure and currency unions - are found not to be robust.

Marianne Baxter

Department of Economics Boston University

270 Bay State Road

Boston, MA 02215

and NBER

mbaxter@bu.edu

Michael A. Kouparitsas

Research Department

Federal Reserve Bank of Chicago

230 South LaSalle Street

Chicago, IL 60604

mkoup@frbchi.org 


\section{Introduction}

There is longstanding interest in the channels through which business fluctuations in one country are transmitted to other countries. It is often said that "When America sneezes, Europe catches a cold.” But despite the theoretical and empirical analyses to date, it seems fair to say that there is no consensus on the important determinants of business-cycle comovement. The difficulty is that there are many potential candidate explanations.

One leading candidate is trade. Frankel and Rose (1998) present empirical evidence that higher bilateral trade between two countries is associated with more-correlated business cycles. Another explanation for business-cycle comovement is similarity in industrial structure. This linkage has been stressed in a series of papers by Jean Imbs $(1998,1999,2003)$. A third variable studied by Rose and Engel (2002) is currency unions. Other variables that may be important for business-cycle comovement are the following: (i) the extent of total trade in each country; (ii) factor endowments and (iii) gravity variables such as distance between countries, common language, adjacency, and so on. ${ }^{1}$

Our paper uses a dataset that includes over 100 countries, both developed and developing. We have collected data for each country on each of the variables described above. To say something definite about the important determinants of comovement, we use the “robustness” approach advocated by Leamer (1983), and used so effectively by Levine and Renelt (1992) in their analysis of growth regressions. With this approach, a variable is said to be a robust determinant of business-cycle comovement if the variable has a significant coefficient in a regression when all other potential explanatory variables have had a chance to "knock the variable out of the equation."

Our results are as follows. Nearly all of the variables considered are significant determinants of trade when considered in isolation. However, there are only a few robust variables. Bilateral trade is robust: countries that trade more with each other have morecorrelated business cycles. Further, our results indicate that bilateral trade is robust to the

\footnotetext{
${ }^{1}$ See also papers by Calderon, et al. (2002), Fidrmuc (2002), Kose, et al. (2003), Otto, et al. (2003) and Shin and Wang (2003). These authors study the determinants of business-cycle synchronization using a variety of country samples and economic variables. Recent contributions by Kose and Yi (2001,2004) explore the ability of dynamic, stochastic general equilibrium models to explore various theoretical explanations for the finding that stronger trade linkages are associated with more-correlated business cycles.
} 
inclusion of gravity variables, suggesting an independent role for trade in transmitting business cycles.

Other variables that are robustly, positively related to business-cycle comovement are (i) an indicator variable that indicates that both countries are industrialized countries; (ii) an indicator variable that indicates that both countries are developing countries; (iii) a variable measuring the distance between the two countries. Variables that are not robust include (i) measures of industrial similarity; (ii) currency union; (iii) total trade undertaken by the two countries; (iv) measures of similarity in export and import baskets; and (v) measures of factor intensity.

Our finding that sectoral similarity is not robust stands in contrast to recent research by Imbs $(1998,1998,2003)$ in which he argues that sectoral similarity is strongly positively related to business-cycle correlations. Our finding on currency unions challenges much recent research, initiated by the contribution of Rose and Engel (2002), in which currency union is found to be related to business cycle comovement. Our results show that this relationship is not robust.

\section{Econometric Methodology}

This section describes the econometric methodology used in this paper. Briefly, the approach is Leamer’s (1983) “Extreme Bounds Analysis” applied to band-pass-filtered data. The band-pass filter is designed to isolate business-cycle components of the data. We include country-specific indicator variables to remedy problems associated with using an estimated variable (the business-cycle correlation) as the dependent variable in our regressions. Readers may go directly to section 3 if they prefer to skip the econometric details.

\section{$\underline{2.1 \text { Extreme-Bounds Analysis }}$}

Our analysis will involve regressions of a dependent variable, $\mathrm{Y}$, on various sets of independent variables. Specifically, $\mathrm{Y}$ is a vector of business-cycle GDP correlations $Y_{i j}$ between a pairs of countries $i$ and $j$. We measure the business-cycle component of quarterly real GDP using the BP(6,32) filter described by Baxter and King (1999). Other researchers, such as Frankel and Rose (1998) and Rose and Engel (2002), have employed a variety of filters in their 
related investigations. Frequently, the filter used does not matter importantly for the results. We confine our attention to just one filter because this filter was designed to measure business cycle correlations, which is the focus of this paper. The other filters, such as the first-difference filter, do not provide a good measure of the business-cycle frequencies. See Baxter and King (1999) for more detail.

The econometric approach that we use is the extreme-bounds analysis (EBA) suggested by Leamer (1983). The general form of the regression used for the EBA is as follows:

$$
Y=I \beta_{i}+M \beta_{m}+Z \beta_{z}+u
$$

The independent variables are of three types, as follows. I denotes a set of "alwaysincluded” variables. This set may be empty. The M-variable is the variable which is being tested for robustness. The Z-variables contain other variables that prior studies have suggested may be important for business-cycle correlations. The EBA is performed by varying the set of Z-variables included in the regression for a particular M-variable. From these regressions, the EBA determined the highest and lowest values of confidence intervals constructed from the estimated $\beta_{m}$. We will say that an $\mathrm{M}$-variable is robust if these highest and lowest values are of the same sign (that is: this range does not include the value zero which would indicate that the variable is not significantly related to $\mathrm{Y}$ ).

\section{$\underline{2.2}$ Econometric Issues}

An important econometric problem results from the fact that the econometrician does not observe the true cross-country business cycle correlations $Y_{i j}$, but instead must use estimated correlations $\hat{Y}_{i j}$, which may contain measurement error. To make progress on this problem, it is necessary to make an assumption about the specific form of the measurement error.

We follow the approach taken by many cross-section analyses of large samples in specifying a fixed-effects model:

$$
\begin{aligned}
& \hat{Y}_{i j}=Y_{i j}+V_{i}+V_{j}, \\
& E\left(V_{i}\right)=\alpha_{i},
\end{aligned}
$$


where $V_{i}$ is the fixed effect for country $i^{2}{ }^{2}$ Substituting this into the EBA model above yields the following regression model with a typical equation for correlation pair $i$ and $j$ :

$$
\begin{aligned}
& \hat{Y}_{i j}=I_{i j} \beta_{i}+M_{i j} \beta_{m}+Z_{i j} \beta_{z}+V_{i}+V_{j}+U_{i j}, \\
& E\left(V_{i}\right)=\alpha_{i}, \\
& E\left(V_{i} U_{i j}\right)=E\left(V_{j} U_{i j}\right)=0, \\
& E\left(U_{i j} U_{k l}\right)=\sigma^{2} \text { if } i=k \text { and } j=l, 0 \text { otherwise }
\end{aligned}
$$

This model can be estimated by OLS where indicator variables are used to capture the country fixed effects.

\section{Theory, Measurement and Results}

The goal of this paper is to determine which economic and geographic variables are robustly correlated with business-cycle comovement. In order to interpret the results, it is useful to consider the findings in light of existing theory. At the heart of the issue lie two basic questions. First, why are there business cycles? Second, why are business cycles correlated across countries?

The generally accepted answer to the first question is that business cycles occur because something-random or deliberate--disturbs the steady evolution of an economy along its longrun path. The disturbances may be fiscal policies, monetary policies, changes in technological 'know-how,' or even the weather. Stockman (1988) found that sectoral shocks and national shocks were both important impulses to business cycles. Subsequently, a large literature developed seeking to determine the sources of shocks to national business cycles. ${ }^{3}$ On the theoretical side, there is a large literature of open economy models which study the businesscycle effects of various shocks. Many of these are cited in the survey by Baxter (1995).

\footnotetext{
${ }^{2}$ An alternative approach, utilized by Clark and van Wincoop (2001) and Imbs (2003), assumes a random effects model. There are two advantages to assuming a fixed effects model. First, unlike the random effects model the fixed effects model is robust to measurement error that is correlated with the dependent variables, which is likely to be the case in our EBA analysis. Second, given the large sample size of our EBA regressions random effects is computationally burdensome and from a time perspective not feasible given the large number of regressions we must run.

${ }^{3}$ Contributions include papers by Norrbin and Schlagenhauf (1996), Gregory, Head and Reynauld (1997), Gregory and Head (1999), Clark and Shin (2000), Lumsdaine and Prasad (2003), and Kose, Otrok and Whiteman (2003).
} 
The second question — what causes cross-country correlation between business cycleshas also received substantial attention. The correlation and transmission of business cycles depends on the sources of the disturbances: are the shocks industry-specific or nation-specific? Further, the degree of interconnectedness of the two countries matters. Countries with open capital markets will respond similarly to disturbances which change the world interest rate. Countries that are willing and able to use monetary and fiscal policies may be able to insulate their countries against particular types of shocks, as originally suggested by Mundell (1961).

At present, however, there is no single model that can be said to successfully explain why some countries experience business-cycle comovement while others do not. Similarly, there is no consensus on the predominant sources of shocks to national and international business cycles. This is precisely why we are conducting the present, primarily empirical exercise. Our goal is to isolate those factors that appear to be robustly related to business-cycle correlation.

This section describes in detail the measurement of variables used in our investigation. We have grouped these variables into several sub-groups, according to the economic phenomenon that the variable is intended to measure. The details of the data sources and variable definitions are presented in Appendix A. We will consider measures of international trade, industrial structure, factor endowments, and currency union. We will also consider the socalled "gravity variables"- exogenous characteristics of country pairs that have been shown to explain a great deal of bilateral trade. The results reported in the text of the paper have all been estimated with country fixed effects. For the interested reader, we have reported complete results without country fixed effects in Appendix B. The results are quite insensitive to the removal of the country fixed effects.

Table 1 presents the correlation coefficients among all the variables used in our study. The first column of the table contains the correlations between the business-cycle correlation and the other variables. The variables are grouped according to the phenomenon they capture: bilateral trade intensity, total trade intensity, etc. The details of the construction of each variable are explained in the subsections below, and we will refer back to this table frequently. The within-group correlations are shaded for ease of reference. We turn now to a detailed consideration of each group of variables.

\section{$\underline{3.1 \text { Gravity variables }}$}


In the existing literature, there is abundant evidence that the gravity variables can explain bilateral trade. ${ }^{4}$ Further, several recent papers have shown that bilateral trade is trade is related to business-cycle comovement. ${ }^{5}$ We begin the empirical analysis by studying the relationship between business-cycle comovement and the exogenous gravity variables: adjacency, distance, common language, population variables, total land, and indicator variables for two industrialized countries and two developing countries.

Table 2-A presents a regression of the business-cycle correlation on a typical set of gravity variables, ignoring country fixed effects. Variables significant at the $10 \%$ level include adjacency, distance, minimum population, the land variables and dummies indicating both industrial and both developing countries.

For comparison with our later results, Table 2-B presents results that combine the gravity variables with country fixed effects. Including the country fixed effects leads to collinearity between pairs of gravity variables that measure maximum and minimum values of a particular variable. Thus Table 2-B includes only one variable from each pair of this type-we choose the "minimum" value. We find that adjacency, common language, distance, minimum population and industrial country indicator are all significant.

In our analysis of the other variables, we use the gravity variables in two ways. First, we allow the gravity variables to act as Z-variables in the EBA regressions. Second, we use the set of gravity variables as I-variables (always-included variables) in the EBA regressions. The point of including gravity variables as I-variables is to control for that part of business-cycle comovement that is strictly exogenous to the country pair. Overall, our results are affected very little by whether the gravity variables are Z-variables or I-variables.

\section{$\underline{3.2 \text { Bilateral trade }}$}

The relationship between trade and business cycles has received a great deal of attention, both in theoretical and empirical work. At the heart of this lies the question of why countries

\footnotetext{
${ }^{4}$ See Frankel and Rose (1998).

${ }^{5}$ See Frankel and Rose (1998), Imbs (1998, 1999, 2003), and Clark and van Wincoop (2001).
} 
trade in the first place. The secondary question, which cannot be addressed until the first question is answered, is "how does trade affect business cycles?"

Classical Ricardian theory explains trade as resulting from the fact that trade permits exploitation of gains from greater specialization. Modern theories that have a strongly Ricardian flavor include those by Baxter (1992), Eaton and Kortum (2002), and Alvarez and Lucas (2004). Models in which the gains from trade arise from increasing returns to scale are summarized in Helpman and Krugman (1985). In all these theories, increased trade results in increased sectoral specialization.

What are the implications of increases in trade and specialization for international business cycles? If the primary disturbances are sector-specific, then specialization should lead to decreased business-cycle correlation. On the other hand, trade may act as a conduit for the transmission of shocks that affect all industries. In this case, increased trade would lead to increased business cycle correlation.

The empirical relationship between trade and business cycles has been studied by several authors, beginning with work by Canova and Dellas (1993). Frankel and Rose (1998) found that bilateral trade was positively related to business-cycle comovement. Clark and van Wincoop (2001) also find that higher trade is related to more-highly-correlated business cycles. Gruben, et al. (2002) explore alternative econometric procedures and also include variables measuring the structure of trade. All these studies all conclude that trade is strongly, positively correlated with business cycle comovement. $^{6}$

We construct four measures of bilateral trade intensity. The measures differ from one another in two ways: (i) the date at which the measure is calculated; we use both the beginning date and the ending date; and (ii) the scale variable used to normalize the bilateral trade measure: we use total trade and also aggregate GDP across the two countries.

The measure BT1 is defined as

$$
B T 1_{i j}=\frac{x_{i j}+m_{i j}+x_{j i}+m_{j i}}{x_{i}+m_{i}+x_{j}+m_{j}}
$$

\footnotetext{
${ }^{6}$ Frankel and Rose also study an instrumental-variables version of the regression in which gravity variables are used as instruments for bilateral trade. They find that the coefficient estimates are larger with instrumental-variables estimation.
} 
where $x_{i j}$ is the 1970 (beginning of sample) value of exports from country $i$ to country $j, m_{i j}$ is the 1970 value of imports from country $i$ to country $j, x_{i}$ is the 1970 value of country $i$ 's exports to all countries and $m_{i}$ is the 1970 value of country $i$ 's imports from all countries. The measure BT3 uses the same formula as BT1, except that 1995 (end of sample) values are used. Measures BT1 and BT3 are very similar to the “preferred measure” used by Frankel and Rose (1998).

The measures BT2 and BT4 are constructed according to the following formula, where BT2 uses 1970 values and BT4 uses 1995 values, and where $y_{i}$ is the value of country $i$ 's GDP:

$$
B T 2_{i j}, B T 4_{i j}=\frac{x_{i j}+m_{i j}+x_{j i}+m_{j i}}{y_{i}+y_{j}} .
$$

In summary, BT1 and BT3 express bilateral trade as a fraction of total trade, at the beginning and end of the sample period, respectively. The variables BT2 and BT4 express bilateral trade as a fraction of aggregate GDP in the two countries, at the beginning and end of the sample period.

\subsubsection{A First Look}

The measure BT1 is our preferred measure of bilateral trade, for two reasons. First, it measures trade at the beginning of the sample, which we will compare to business-cycle correlation over the subsequent sample period. Thus the direction of causality is clear. Second, we prefer the measure that uses total trade as the scale variable, rather than total GDP.

Figure 1 is a scatter plot showing the extent of bilateral trade at the beginning of the sample (measure BT1) on the horizontal axis, and the corresponding business-cycle correlation on the vertical axis. Each country-pair is a point on this plot. The univariate regression line of the business-cycle correlation, denoted $\boldsymbol{y}$, on the BT1 measure of bilateral trade, denoted $\boldsymbol{x}$, is indicated by the heavy solid line on the graph. The details of this univariate regression are also given. The slope is positive and significant, although the R-square is only 0.034. Some of the outliers are labeled.. For the most part, those country pairs that have both high bilateral trade and high business-cycle correlation are ones where this relationship might be expected. For example, the US and Canada have the highest bilateral trade measure, and also have highly correlated business cycles. Other country pairs of this type include Singapore/Malaysia, US/Japan and 
France/Germany. One might worry that the outliers are responsible for the positive estimated slope coefficient. However, there are over 5000 observations plotted on this graph. If we remove the 20 observations for which BT1 exceeds 0.10 , the slope coefficient actually rises and is still significant. Thus the positive relationship is not due to a few extreme observations.

\subsubsection{Testing for Robustness}

Table 3 presents the results of the base regressions for each of the four bilateral trade variables, together with the extreme bounds analysis for these variables. The top panel of the table conducts the analysis with no "always-included" variables. For each bilateral trade variable, we report the coefficients $\left(\beta_{m}{ }^{\prime} s\right)$ with the highest and lowest confidence intervals. We also present the standard error of $\beta_{m}$ in each case, the t-statistic for the null hypothesis that $\beta_{m}=0$, the number of observations, and the R-square of the regression. In the second-to-last column we report the other variables (the Z-variables) in the regression that yielded the high/low estimates. The final column reports on the robustness of the M-variable. The variable is said to be robustly correlated with cyclic comovement if the high and low values of all confidence intervals for the estimated $\beta_{m}$ 's are of the same sign.

The bottom panel of the table contains results for which the gravity variables are "always-included” I-variables. The gravity variables are: adjacency, distance, common language, population variables, total land, and indicator variables for two industrialized countries and two developing countries. The purpose of having the gravity variables always-included is to control for that part of business-cycle correlation which can be viewed as exogenous.

The reason for including the gravity variables is as follows. In the existing literature, there is abundant evidence that the gravity variables can explain bilateral trade, and that trade is related to business-cycle comovement. This raises a natural question of whether there is anything left for variables such as bilateral trade, industrial structure, or monetary union to explain, once the exogenous gravity variables are included in the regression.

Looking first at the base regressions with no always-included variables, we find that all four measures of bilateral trade intensity have positive coefficients which are 
statistically significant. ${ }^{7}$ These variables continue to be significant in the base regressions even when the gravity variables are included (bottom panel of Table 3). This is somewhat surprising, as the gravity variables have long been known to be very good at explaining the extent of bilateral trade. We expected that including the gravity variables might eliminate the statistical significance of the bilateral trade variables, but this is not the case.

We turn now to the "robustness" tests—-the extreme bounds analysis (EBA). Throughout, we use a $10 \%$ critical value. All four measures of bilateral trade intensity are robust when there are no always-included variables. When the gravity variables are included, only one of the four measures continues to be robust. The robust measure is BT1, which is our preferred measure for reasons given above. In all cases, the sign of the coefficient on bilateral trade is positive, indicating that higher levels of bilateral trade are associated with higher business-cycle correlation. Comparing the coefficients on the trade variables with and without the gravity variables included, we find that including the gravity variables reduces the size of the estimated coefficient in all cases, by approximately $30-50 \%$.

\section{$\underline{3.3 \text { Extent of Total Trade }}$}

The next variable we consider is the extent of total trade carried out by the pair of countries. In contrast to the bilateral trade measure, the total trade measure is intended to capture the general "openness" of the two countries. ${ }^{8}$ Just "openness" may matter; it may not be important how much bilateral trade there is, rather, the total amount of trade may be important. This variable may capture the flow of technological transmission that occurs through trade in general, not with a specific trading partner. Another possibility is that the extent of total trade is a good measure of the extent to which the country is exposed to global shocks. Thus it is possible that higher trade, in the aggregate, leads to more-highly-correlated business cycles.

\footnotetext{
${ }^{7}$ The base regressions include country fixed effects, while the regressions in the scatter plots do not. Thus the coefficient estimates differ between the two specifications.

${ }^{8}$ Many empirical investigations that wish to measure the openness of an economy use the amount of total trade as a proxy for openness.
} 


\subsubsection{A first look}

Figure 2 presents a scatter plot of total trade against business-cycle correlation. The specific measure of total trade plotted here is TT1, defined as

$$
T T 1_{i j}=\frac{x_{i}+m_{i}+x_{j}+m_{j}}{y_{i}+y_{j}}
$$

where $x_{i}$ and $m_{i}$ denote total exports and imports, respectively, for country $i$, measured at the beginning of the sample in 1970. We also construct an end-of-sample measure, TT2, using 1995 data.

Figure 2 shows that there is a positive, significant relationship between total trade and business-cycle correlation. For most countries, total trade is a very small fraction of GDP, and this is reflected in the "cloud" of observations clustered between 0.00 and 0.25 on the TT1 axis. Further, the R-square of 0.0042 is extremely small.

\subsubsection{Testing for robustness}

Table 4 presents the detailed results for the two measures of total trade. In the base regressions, the coefficient is always negative, and also significant. Considered in isolation, higher total trade is associated with lower business-cycle correlation. It is difficult to think of a good economic reason why this ought to be the case. However, the EBA shows that the total trade variables are fragile, whether or not the gravity variables are included. Once other variables are considered, there is no independent role for total trade in explaining business-cycle correlation.

\subsection{Similarity of Industrial Structure}

If the primary business-cycle shocks are sector-specific, then countries with greater similarity in sectoral structure would tend to have more-correlated business cycles, other things equal. Stockman (1988) showed that sectoral shocks were one important impulse to business cycles. In a sequence of empirical papers, Imbs (1998, 
1999, 2003) has presented results showing that similarity of industrial structure is significantly, positively related to business-cycle correlations. In his 1998 paper, using quarterly data for 21 OECD countries, Imbs finds that bilateral trade is not important for business cycles once country fixed effects are included.

We will study six measures of industrial similarity. These measures have been chosen for comparability with existing research. We have also tried to include several alternative, reasonable methods for defining industrial similarity. Our first measure of industrial similarity, suggested by Shea (1996) and used by Imbs (1998, 1999), is the correlation of sectoral shares:

$$
I S C 1_{i j}=\frac{\sum_{n=1}^{N} s_{i n} s_{j n}}{\sqrt{\sum_{n=1}^{N} s_{i n}^{2}} \sqrt{\sum_{n=1}^{N} s_{j n}^{2}}} .
$$

where 'sectors' are defined as one of seven sub-sectors of aggregate GDP The variable ISC1 takes on values in the interval $[0,1]$. Greater similarity in sectoral structure leads to larger values of ISC1. If $s_{i n}=S_{j n}$ so that sectoral shares of each industry are the same across countries, ISC1 is equal to 1.

Some studies look only at the structure of manufacturing, so we define a comparable measure for manufacturing alone. Our manufacturing index ISC2 uses 3-digit-level manufacturing data for 30 industries, defined as:

$$
I S C 2_{i j}=\frac{\sum_{n=1}^{N} s_{i n} s_{j n}}{\sqrt{\sum_{n=1}^{N} s_{i n}^{2}} \sqrt{\sum_{n=1}^{N} s_{j n}^{2}}} .
$$

where the industry subscripts, $n$, now refer to manufacturing industries.

The next measure of industrial similarity is:

$$
I S S 1_{i j}=1-\sum_{n=1}^{N}\left(s_{i n}-s_{j n}\right)^{2}
$$


where $s_{i n}$ is the sector- $n$ fraction of GDP of country $i$. If $s_{i n}=s_{j n}$ so that sectoral shares of each industry are the same across countries, ISS1 is equal to one. More generally, higher levels of sectoral similarity result in higher values of ISS1. We also construct ISS2, which is the corresponding measure using manufacturing data.

Finally, we construct a third pair of measures similar to those used by Clark and van Wincoop (2001) and Imbs (2003). This measure of sectoral similarity uses absolute values of differences in sectoral shares:

$$
I S A 1_{i j}=1-\sum_{n=1}^{N}\left|s_{i n}-s_{j n}\right|
$$

If $s_{i n}=S_{j n}$ so that sectoral shares of each industry are the same across countries, ISA1 is equal to one. ISA2 uses the same definition applied to manufacturing data. As with all our measures, higher values of ISA1 and ISA2 indicate greater similarity in industrial structure.

We refer back to Table 1 to look at the correlations among these variables. This table shows that there is low correlation between a particular measure constructed from GDP data and the same measure constructed from manufacturing data. Specifically, the correlation between ISS1 and ISS2 is 0.29; the correlation between ISA1 and ISA2 is 0.30 , and the correlation between ISC1 and ISC2 is 0.23 . Since these correlations are low, we will allow the manufacturing measures as Z-variables in regressions where a corresponding GDP measure is the M-variable, and vice-versa (e.g., ISS1 and ISS2; ISA1 and ISA2; and ISC1 and ISC2). However, the correlations among all the GDP measures is high (in absolute value), as are the correlations among the manufacturing measures. Thus, if one GDP measure, (e.g., ISC1) is an M-variable, then other GDP measures (e.g., ISS1 or ISA1) will not be included as Z-variables.

\subsubsection{A first look}

Figure 3 presents a scatter plot of ISC1 and business-cycle correlation. There is considerable dispersion in the scatter plot. A glance at the points themselves does not obviously imply any relationship between these variables. The solid line is the estimated regression line from a regression of the business-cycle correlation on ISC1. The details of the estimate are shown on the graph. The estimate of the slope coefficient is 0.17 , with a standard error of 0.03 . 
The R-square of the regression is 0.013. Thus, industrial structure is indeed significantly, positively related to business-cycle correlation when considered in isolation.

\subsubsection{Testing for robustness}

Table 5 presents the results of the EBA for the industrial similarity variables. The "base" regressions show that each of the six measures of industrial similarity has a positive and significant coefficient when considered alone. This is true whether the gravity variables are included or not. The coefficient estimates in these base regressions range from 0.11 to 0.36 . Thus, taking the high estimate of 0.36 , an increase in sectoral correlation from, say, 0.30 to 0.50 would be accompanied by an increase in the business-cycle correlation of $0.20 * 0.36=0.072$. This is not a large increase, but still of economic interest if it is robust.

However, the EBA finds that all the industrial structure variables are fragile, independent of whether the gravity variables are included as I-variables. Although most of the point estimates of the coefficients are always positive, the confidence intervals for the "low" estimates include negative numbers.

To try to understand what may be leading to the fragility, we look at the "other variables" - the Z-variables—included in the "low” regressions. In the top panel, with no always-included variables, we find that bilateral trade variables appear in 5 of the 6 "low" regressions in which the industrial structure variable is not statistically significant. Trade similarity variables appear in 3 regressions, while a factor endowment variable (one or more of MAXK, MINK, MINED, MAXED, described in detail in the next section) appears in all 6. The indicator for developing countries appears twice, while the indicator for the developed countries appears once.

When we look at the regressions with the gravity variables always-included, we find that the bilateral trade variables do not appear in any of the extreme-value regressions (neither "high" nor “low”). Factor endowment variables measuring labor and capital again appear in all six regressions, as do trade similarity measures. Total trade variables appear in two regressions. The developing/industrialized indicators are included in the I-variables and therefore were not considered as Z-variables.

What can we infer from this pattern of Z-variables in the regressions that lead to the result of fragility? Broadly, it appears that inclusion of factor-endowment variables, especially 
endowments of labor and capital, reduce the influence of industrial structure to insignificant levels. Traditional Heckscher-Ohlin theory predicts a strong relationship between factor endowments and the sectoral structure of production. Other trade theories, notably modern Ricardian theories in which factor accumulation is endogenous, predict a strong relationship between the production structure and the relative supplies of factors in the economy. ${ }^{9}$ Thus it may not be surprising that including factor endowments leads to fragility of the industrial structure variables. Bilateral trade and the structure of trade also appear frequently in regressions with insignificant coefficient estimates for industrial structure. Again, all trade theories predict a tight relationship between factor endowments, production, and the extent and type of trade. Nevertheless, we found (in Section 3.2 above) that bilateral trade was robustly related to business-cycle correlation, even when the Z-variables included industrial structure, factor endowments, trade structure, etc. The results of this section are that industrial structure is not similarly robust.

\subsection{Similarity in Baskets of Traded Goods}

We considered similarity in baskets of traded goods as one possible economic variable that could be related to business-cycle comovement across countries. For example, if countries export and/or import similar baskets of goods, then they would be affected similarly by shocks to the world prices of their import and export goods. In addition, countries with similar baskets of traded goods would be affected similarly in the event of sector-specific shocks hitting their export and/or import sectors.

For completeness, we define nine measures of trade similarity: three groups of three measures each. The three groups parallel the three groups used for the industrial similarity measures. The first group uses a correlation coefficient, identified by the mnemonic TSC. The second group uses square of differences in sectoral shares, identified by the mnemonic TSS. The third group uses the absolute values of differences in sectoral shares, identified by the mnemonic TSA. Within each group, we construct a measure comparing (i) total export shares using 2-digit SITC data for all country pairs, denoted by “1” as the last digit of the variable name; (ii) total import shares using 2-digit SITC data for all country pairs, denoted by " 2 ” as the last digit of the variable name; and (iii) bilateral export shares using 2 digit SITC data for all country pairs,

\footnotetext{
${ }^{9}$ See Baxter (1992).
} 
denoted by "3" as the last digit. Thus, TSC3 refers to the correlation coefficient measure of trade similarity (TSC), using data bilateral export shares (“3”).

The correlation matrix reported in Table 1 shows that there is high correlation between (i) TSS1, TSA1 and TSC1; (ii) TSS2, TSA2 and TSC2; and (iii) TSS3, TSA3 and TSC3. Correlation (in absolute value) is small among other pairs of the trade similarity variables. To avoid multicollinearity we select variables for the regressions as follows. When the M-variable is TSS1 trade similarity variables from the same group are permitted as Z-variables (i.e, TSS2 and TSS3), while the highly-collinear variables TSA1, TSC1 are excluded from the set of Zvariables. A similar rule is used for the other variable groups.

\subsubsection{A first look}

Figure 4 presents a scatter plot of TSC3 and the business-cycle correlation. A glance at the highly dispersed scatter gives a general impression that there is no relationship between these variables. However, there is a weak, but significant, negative relationship between the similarity of the structure of bilateral trade (TSC3) and the business-cycle correlation.

\subsubsection{Robustness analysis}

As described above, we constructed nine measures of similarity in traded goods, comprising three sets of three different measures. The three sets are distinguished by the basket

of goods considered. The first uses total exports, the second uses total imports, and the third uses bilateral exports. Within each set, there are three measures which are constructed in a manner analogous to the three measures of industrial similarity.

Table 6 presents the robustness analysis for the trade-similarity variables. Looking first at the "base" regressions, we find that most of the trade-similarity variables are not significant, even without the addition of Z-variables. All the coefficients but one are positive, but very small. Less than half are significant.

The EBA analysis finds that none of the trade-similarity variables is robust. This finding is independent of whether the gravity variables are included as Z-variables. The Z-variables that appear in the "low" regressions include industrial similarity variables and bilateral trade variables. Apparently, given observations on industrial similarity and bilateral trade, there is 
nothing to be added by including trade similarity as an explanatory variable for business cycle correlation. Given the tight link between these three variables that is implied by trade theory, this finding is perhaps not very surprising.

\section{$\underline{\text { 3.6 Factor Endowments }}$}

Most theories of interacting economies predict a significant relationship among factor endowments, trade, and business-cycle comovement. This would be true of standard Heckscher-Ohlin theory, and would also be true of Ricardian theories. Hybrid models that combine elements of monopolistic competition in manufacturing with competitive markets in other goods would also imply a relationship among these variables. We consider three factors of production: human capital (measured as log of years of education); log of physical capital per worker, and log of arable land per worker. In each case, we consider variables measuring the minimum value of the variable between the two countries, as well as the maximum value of the variable. ${ }^{10}$

\subsubsection{A first look}

We begin by taking a closer look at one particular measure of factor endowments: a variable measuring the log of the minimum education level between the two countries, MINED. Figure 5 presents a scatter plot of this variable against the business-cycle correlation. The scatter plot reflects the fact that MINED takes on several discrete values. The estimated univariate regression line shows a positive and significant relationship. The higher is the minimum education level between the two countries, the higher is the business-cycle correlation between the two countries. However, the scatter is highly dispersed, and the R-square of the regression is only about 0.04. Clearly,

\footnotetext{
${ }^{10}$ As noted earlier, the inclusion of country fixed effects leads to collinearity between maximum and minimum measures of a given economic variable. For completeness we report the results for all variables. However, it will be apparent that the coefficients on the minimum M-variables have equal and opposite signs from the corresponding maximum variables.
} 
MINED does not explain a great deal of the cross-sectional variance in the business-cycle correlation.

\subsubsection{Robustness analysis}

Table 7 presents the complete results for the factor endowment variables. We begin by looking at the top panel which summarizes results with no Z-variables. Education and capital variables are all significant in the base regressions

The minimum-education variable (MINED) has a positive and significant coefficient, while the maximum-education variable (MAXED) has a negative and significant coefficient. Similarly, the minimum-capital variable (MINK) is positive and significant, while the maximum-capital variable (MAXK) is negative and significant. By contrast, the land variables are not significant, although they show the same pattern in the signs of the coefficients: positive for minimum-land (MINL) and negative for maximum land (MAXL).

In the bottom panel, showing results for which the gravity variables are Zvariables, we find the same pattern of signs of the coefficients. However, the magnitudes of the coefficients are reduced by half or more, and the variables are no longer significant, except for the two capital variables.

The EBA reveals that none of the factor-endowment variables is robust, independently of the inclusion of Z-variables. Variables that appear in the "high" and "low" regressions include total trade, industrial similarity, other factor intensity variables (notably capital and education), bilateral trade, and trade similarity. There is thus no clear pattern that can explain why the factor endowment variables fail to be robust.

\section{$\underline{3.7 \text { Currency Union }}$}

Since Mundell (1961), economists and policymakers have been interested in the economic requirements for, and effects of, currency union. More recently, the formation of the European Monetary Union in 1999 has led to abundant research on the effects that currency 
unions have on trade and business-cycle characteristics of member countries. Frankel and Rose (1998) point out that countries with more-similar business cycles are more natural candidates for membership in a common-currency area. Further, the currency union itself might change the nature of bilateral business cycles. Theories of the way in which this might happen are summarized in more detail in papers by Frankel and Rose $(1998,2002)$. Most theories predict that a common currency will reduce intra-union barriers to trade and will thereby lead to greater intra-union trade in goods and capital. However, the theories differ in their predictions for the effect of this increased trade on business-cycle comovement. Increased trade will lead to reduced comovement if the result of increased trade is greater specialization in a setting with shocks that are predominantly industry-specific. Increased trade will lead to increased comovement if the main source of shocks are demand shocks that are common across countries. One source of shocks might be the common monetary policy.

Most recent empirical evidence suggests that currency union leads to increased businesscycle correlation among member countries. Kim (1995) shows that the industrial structure of the 50 U.S. states has become much more alike in the 90 years following the formation of the U.S. common currency area (U.S. Federal Reserve System), which suggests regions do not specialize in the production of goods under a currency union. Rose and Engel (2002) estimate the effect of currency unions on between business cycle comovement. They find that the coefficient on the currency unions is positive. However, significance of this coefficient is not robust to the changes in the set of additional explanatory variables.

Table 8 presents the robustness analysis for the currency union variable. Because the currency union variable is a binary (dummy) variable, we do not present a scatter plot of this variable against the business-cycle correlation (as we did for all other variables). Table 8 shows that the currency union variable carries a significant coefficient in the base regression when the gravity variables are not included. The estimated coefficient in the base coefficient is 0.08 , implying that membership in a currency union increases the business-cycle correlation by 0.08 . The coefficient on the currency union variable is not significant in the base regression that includes the gravity variables as Z-variables. The point estimate has dropped to 0.03 , and the standard error is also 0.03 . 
Currency union is found to be fragile in the extreme-bounds analysis. The "high" and "low" values of the confidence intervals are similar whether or not the gravity variables are included as Z-variables. The Z-variables that lead to the "high" estimates are industrial similarity (ISC1, ISC2); and trade similarity, TSC3. The Z-variables found in the "low" regressions are total trade (TT1), industrial similarity (ISA1), and the minimum-education variables (MINED).

In summary, we find that currency union is not a robust predictor of business-cycle correlation. Currency union is only a significant predictor of business cycle correlation if other variables are not included in the regression.

\subsection{A Return to the Gravity Variables}

It is well-known that a large fraction of bilateral trade can be explained, in a statistical sense, by a set of "gravity variables" which include distance between countries, indicator variables for common language and adjacency, and variables which measure the difference the countries levels of GDP. To this point, the gravity variables have been included in the analysis as a set of "always-included" variables, the results of which are shown in the bottom panel of Tables 3-8. It is notable that the robustness results obtained for the other variables have been largely invariant to whether the gravity variables were included or not. In this section, we investigate whether the any of the gravity variables is a robust explanatory variable for businesscycle correlation.

\subsubsection{A first look}

The distance between two countries is one variable that is routinely included in "gravity regressions" for which bilateral trade is the dependent variable. Many of our gravity variables are binary (dummy) variables, but distance is not. Thus it is a good candidate for graphing in a scatter plot. Figure 6 plots the log of distance against the business-cycle correlation. As in all of our graphs, the scatter is very diffuse. The estimated regression equation shows that there is a significant negative relationship between distance and business-cycle correlation. Countries that are located closer to each other have, other things equal, more-highly-correlated business cycles. 
There are many reasons to expect that this would be the case. For example, regional shocks to weather would affect countries similarly if they are located near each other. Countries trade more if they are located closer together (this is why the gravity equations work so well in the first place), and if shocks are transmitted through trade, then we would expect distance to be related to business-cycle comovement. However, we might also wonder whether there is anything left for distance to explain, once bilateral trade is taken into account. The EBA allows us to answer precisely these types of questions.

\subsubsection{Robustness analysis}

Table 9 presents the EBA of the gravity variables. We have included maximum-GDP and minimum-GDP variables as potential Z-variables, since these are frequently used in gravity regressions. We have not included them previously as I-variables since they cannot be viewed as exogenous with respect to the various $\mathrm{M}$-variables.

Our findings are as follows. The log of distance is found to be robustly, negatively related to business-cycle correlation. Since the coefficient on distance is negative, it is the "high" regression for which the confidence interval comes closest to including the value of zero. In this regression, we find bilateral trade (BT3) as one of the Z-variables. This is in line with our intuition that distance may affect business-cycle correlation through its effect on bilateral trade. But, we also find that distance is significant even after bilateral trade is taken into account.

There are only two other robust gravity variables: these are the indicator variables for (i) two industrialized countries; and (ii) two developing countries. The coefficient is positive in each case. This means that the business-cycle correlation is higher if the countries are of similar "types"-both developing or both industrialized. The business-cycle correlation is lower if one country is developing and one is developed. To the extent that intra-industry trade drives trade between industrialized countries, and to the extent that sectoral shocks predominate, we might expect the finding for industrialized countries. However, we view the finding for developing countries as surprising and worth further thought and analysis.

The other gravity variables are all fragile. These include adjacency; common language; minimum and maximum log population variables, and minimum and maximum log total land variables. Adjacency and common-language were both significant in the base regressions, but 
were found to be fragile once Z-variables were considered. The population and total-land variables were not significant even in the base regressions.

\section{Conclusion}

This paper has investigated the robustness of correlations between business-cycle comovement and a host of economics variables. Our key findings are as follows.

(i) Higher bilateral trade between two countries is robustly correlated with a higher businesscycle correlation between the countries. The finding that trade is robust emerges both with and without the gravity variables playing the role of "always-included” I- variables. The fact that bilateral trade is robust even when the gravity variables are included indicates that bilateral trade matters for business-cycle comovement separately from the effects on trade occurring through the gravity variables.

(ii) Greater similarity in industrial structure is not robustly correlated with business-cycle correlations. Although industrial structure variables are significant in the base regressions (with no other explanatory variables), the significance disappears when the full set of Z-variables is considered. This finding occurs with and without the gravity variables as I-variables. This finding indicates that the findings of Imbs $(1998,1999,2003)$ which stress the importance of industrial structure, are fragile.

(iii) Countries belonging to a currency union do not have significantly more highly correlated business cycles than countries that do not share a common currency. This finding calls into question the prior empirical findings of Rose and Engel (2002).

(iv) Two indicator variables were found to be robust. The first indicates that both countries in the pair are industrialized countries; the second indicates that both are developing countries. In both cases, the variables are positively related to business-cycle correlation.

(v) Only one "gravity" variable was found to be robust: this variable is the distance between the two countries. Distance is negatively related to business-cycle correlation, as one would expect. 
Our other findings are negative, in the sense that we found many variables not to be robust. Specifically, total trade measures are fragile, as are the measures of the similarity of total and bilateral trade. Factor endowment variables, including measures of education, capital, and arable land, were all found to be fragile. All gravity variables except for distance were found to be fragile.

In conclusion, our goal in writing this paper was to clarify the relationship between business-cycle comovement and other economic variables. In doing so, we hope to provide guidance for future theoretical and empirical investigations into the sources and propagation mechanisms of international business cycles. 


\section{APPENDIX A: Data Sources and Definitions}

\begin{tabular}{|l|l|}
\hline Variable & Definition and Source \\
\hline Bilateral Trade & \\
\hline BT1 & $\begin{array}{l}\text { Ratio of bilateral trade to total trade in 1970 (Source: } \\
\text { Feenstra, Lipsey and Bowen, 1997, World Trade } \\
\text { Flows CD-ROM, 1970-1992) }\end{array}$ \\
\hline BT2 & $\begin{array}{l}\text { Ratio of bilateral trade to GDP in 1970 (Sources: } \\
\text { Feenstra, Lipsey and Bowen, 1997, World Trade } \\
\text { Flows CD-ROM, 1970-1992, and Penn World Tables } \\
\text { version 5.6) }\end{array}$ \\
\hline BT3 & $\begin{array}{l}\text { Ratio of bilateral trade to total trade in 1995 (Source: } \\
\text { Feenstra, 2000, World Trade Flows CD-ROM, 1980- } \\
\text { 1997) }\end{array}$ \\
\hline BT4 & $\begin{array}{l}\text { Ratio of bilateral trade to GDP in 1995 (Sources: } \\
\text { Feenstra, 2000, World Trade Flows CD-ROM, 1980- } \\
1997, \text { and Penn World Tables version 5.6) }\end{array}$ \\
\hline Total Trade & $\begin{array}{l}\text { Ratio of total trade to GDP in 1970 (Sources: } \\
\text { Feenstra, Lipsey and Bowen, 1997, World Trade } \\
\text { Flows CD-ROM, 1970-1992, and Penn World Tables } \\
\text { version 5.6) }\end{array}$ \\
\hline TT1 & $\begin{array}{l}\text { Ratio of total trade to GDP in 1995 (Sources: } \\
\text { Feenstra, 2000, World Trade Flows CD-ROM, 1980- } \\
\text { 1997, and Penn World Tables version 5.6) }\end{array}$ \\
\hline TT2 & $\begin{array}{l}\text { Broad industry similarity, squared difference in 1980 } \\
\text { (Source: United Nations Statistical Yearbook 46 }\end{array}$ \\
\hline Issue on CD-ROM)
\end{tabular}




\begin{tabular}{|l|l|}
\hline & $\begin{array}{l}\text { correlation in 1980 (Source: United Nations Industrial } \\
\text { Development Organization, 2000, Industrial Statistics } \\
\text { Database on CD-ROM) }\end{array}$ \\
\hline Trade Similarity & $\begin{array}{l}\text { Export similarity, squared difference in 1980 } \\
\text { (Sources: Feenstra, 2000, World Trade Flows CD- } \\
\text { ROM, 1980-1997) }\end{array}$ \\
\hline TSS1 & $\begin{array}{l}\text { Import similarity, squared difference in 1980 } \\
\text { (Sources: Feenstra, 2000, World Trade Flows CD- } \\
\text { ROM, 1980-1997) }\end{array}$ \\
\hline TSS3 & $\begin{array}{l}\text { Similarity of bilateral trade flows, squared difference } \\
\text { in 1980 (Sources: Feenstra, 2000, World Trade Flows } \\
\text { CD-ROM, 1980-1997) }\end{array}$ \\
\hline TSA1 & $\begin{array}{l}\text { Export similarity, absolute difference in 1980 } \\
\text { (Sources: Feenstra, 2000, World Trade Flows CD- } \\
\text { ROM, 1980-1997) }\end{array}$ \\
\hline TSA2 & $\begin{array}{l}\text { Import similarity, absolute difference in 1980 } \\
\text { (Sources: Feenstra, 2000, World Trade Flows CD- } \\
\text { ROM, 1980-1997) }\end{array}$ \\
\hline TSA3 & $\begin{array}{l}\text { Similarity of bilateral trade flows, absolute difference } \\
\text { in 1980 (Sources: Feenstra, 2000, World Trade Flows } \\
\text { CD-ROM, 1980-1997) }\end{array}$ \\
\hline TSC1 & $\begin{array}{l}\text { Export similarity, goods share correlation in 1980 } \\
\text { (Sources: Feenstra, 2000, World Trade Flows CD- } \\
\text { ROM, 1980-1997) }\end{array}$ \\
\hline TSC2 & $\begin{array}{l}\text { Import similarity, goods share correlation in 1980 } \\
\text { (Sources: Feenstra, 2000, World Trade Flows CD- } \\
\text { ROM, 1980-1997) }\end{array}$ \\
\hline TSC3 & $\begin{array}{l}\text { Similarity of bilateral trade flows, goods share } \\
\text { correlation in 1980 (Sources: Feenstra, 2000, World } \\
\text { Trade Flows CD-ROM, 1980-1997) }\end{array}$ \\
\hline MINED & $\begin{array}{l}\text { Log of minimum bilateral average years of schooling } \\
\text { for total population 15 years and older (Source: Barro } \\
\text { and Lee, 199?) }\end{array}$ \\
\hline $\begin{array}{l}\text { Log of maximum bilateral average years of schooling } \\
\text { for total population 15 years and older (Source: Barro } \\
\text { and Lee, 199?) }\end{array}$ \\
$\begin{array}{l}\text { Log of minimum bilateral capital per worker using } \\
\text { aggregate investment in 1980 (Source: Easterly and } \\
\text { Levine, 2002) }\end{array}$ \\
$\begin{array}{l}\text { Log of maximum bilateral capital per worker using } \\
\text { aggregate investment in 1980 (Source: Easterly and } \\
\text { Levine, 2002) }\end{array}$ \\
$\begin{array}{l}\text { Log of minimum bilateral arable land (1000s of } \\
\text { hectares) per worker in 1980 (Source: World Bank }\end{array}$ \\
\hline MAXE
\end{tabular}




\begin{tabular}{|l|l|}
\hline & Development Indicators on CD-ROM) \\
\hline MAXL & $\begin{array}{l}\text { Log of maximum bilateral arable land (1000s of } \\
\text { hectares) per worker in 1980 (Source: World Bank } \\
\text { Development Indicators on CD-ROM) }\end{array}$ \\
\hline Currency Unions & $\begin{array}{l}\text { Dummy variable indicating country pair is in } \\
\text { currency union (Source: Frankel and Rose, 2002) }\end{array}$ \\
\hline CU & $\begin{array}{l}\text { Dummy variable indicating one country maintains a } \\
\text { currency board with other currency (Source: Frankel } \\
\text { and Rose, 2002) }\end{array}$ \\
\hline CB & $\begin{array}{l}\text { Dummy variable indicating country pair is part of a } \\
\text { currency union or currency board (Source: Frankel } \\
\text { and Rose, 2002) }\end{array}$ \\
\hline CUB & $\begin{array}{l}\text { Dummy variable indicating common border (Source: } \\
\text { Macalester University, International Trade Database) }\end{array}$ \\
\hline Gravity variables & $\begin{array}{l}\text { Dummy variable indicating common language } \\
\text { (Source: Macalester University, International Trade } \\
\text { Database) }\end{array}$ \\
\hline LANG (2) & $\begin{array}{l}\text { Log of distance in kilometers (Source: Macalester } \\
\text { University, International Trade Database) }\end{array}$ \\
\hline DIST (3) & $\begin{array}{l}\text { Log of minimum bilateral population (Source: Penn } \\
\text { World Tables version 5.6) }\end{array}$ \\
\hline MINPOP(4) & $\begin{array}{l}\text { Log of maximum bilateral population (Source: Penn } \\
\text { World Tables version 5.6) }\end{array}$ \\
\hline MAXPOP(5) & $\begin{array}{l}\text { Log of minimum bilateral total land area (1000s of } \\
\text { hectares) (Source: United Nations Statistical } \\
\text { Yearbook 46 }\end{array}$ \\
\hline MINTL(6) & $\begin{array}{l}\text { Log of maximum bilateral total land area (1000s of } \\
\text { hectares) (Source: United Nations Statistical } \\
\text { Yearbook 46 }\end{array}$ \\
\hline MAXsue on CR-ROM)
\end{tabular}


Notes:

1. Bilateral trade intensity: TB1,TB3 $=\frac{x_{i j}+m_{i j}+x_{j i}+m_{j i}}{x_{i}+m_{i}+x_{j}+m_{j}}$, where $x_{i j}$ is the value of exports from country $i$ to country $j, m_{i j}$ is the value of imports from country $i$ to country $j, x_{i}$ is the value of country $i$ 's exports to all countries and $m_{i}$ is the value of country $i$ 's imports from all countries; and TB2, TB4 $=\frac{x_{i j}+m_{i j}+x_{j i}+m_{j i}}{y_{i}+y_{j}}$, where $y_{i}$ is the value of country $i$ 's GDP.

2. Total trade intensity: TT1,TT2 $=\frac{x_{i}+m_{i}+x_{j}+m_{j}}{y_{i}+y_{j}}$, where $y_{i}$ is the value of country $i$ 's GDP.

3. Broad industry similarity: ISS $1=\frac{1}{N} \sum_{n=1}^{N}\left(s_{i n}-s_{j n}\right)^{2}$, where $s_{i n}$ is the fraction of GDP devoted to sector $n$; ISA2 $=\frac{1}{N} \sum_{n=1}^{N}\left|s_{i n}-s_{j n}\right|$; and ISC1 $=\frac{\sum_{n=1}^{N} s_{i n} s_{j n}}{\sqrt{\sum_{n=1}^{N} s_{i n}^{2}} \sqrt{\sum_{n=1}^{N} s_{j n}^{2}}}$.

4. Manufacturing industry similarity: ISS $2=\frac{1}{N} \sum_{n=1}^{N}\left(s_{i n}-s_{j n}\right)^{2}$, where $s_{i n}$ is the fraction of manufacturing devoted to sub-sector $n$; ISA2 $=\frac{1}{N} \sum_{n=1}^{N}\left|s_{i n}-s_{j n}\right|$; and $I S C 2=\frac{\sum_{n=1}^{N} s_{i n} s_{j n}}{\sqrt{\sum_{n=1}^{N} s_{i n}^{2}} \sqrt{\sum_{n=1}^{N} s_{j n}^{2}}}$.

5. Export similarity: TSS $2=\frac{1}{N} \sum_{n=1}^{N}\left(s_{i n}-s_{j n}\right)^{2}$, where $s_{i n}$ is good $n$ 's share of country i's total exports, $s_{i n}=x_{i n} / x_{i} ;$ TSA2 $=\frac{1}{N} \sum_{n=1}^{N}\left|s_{i n}-s_{j n}\right| ;$ and TSC2 $=\frac{\sum_{n=1}^{N} s_{i n} s_{j n}}{\sqrt{\sum_{n=1}^{N} s_{i n}^{2}} \sqrt{\sum_{n=1}^{N} s_{j n}^{2}}}$. 
6. Import similarity: TSS $2=\frac{1}{N} \sum_{n=1}^{N}\left(s_{i n}-s_{j n}\right)^{2}$, where $s_{i n}$ is good $n$ 's share of country i's total imports, $s_{i n}=m_{i n} / m_{i} ; T S A 2=\frac{1}{N} \sum_{n=1}^{N}\left|s_{i n}-s_{j n}\right| ;$ and TSC2 $=\frac{\sum_{n=1}^{N} s_{i n} s_{j n}}{\sqrt{\sum_{n=1}^{N} s_{i n}^{2}} \sqrt{\sum_{n=1}^{N} s_{j n}^{2}}}$.

7. Bilateral trade similarity: $\operatorname{TSS} 3=\frac{1}{N} \sum_{n=1}^{N}\left(s_{i j n}-s_{j i n}\right)^{2}$, where $s_{i j n}$ is good $n$ 's share of country i's exports to country $j, s_{i j n}=x_{i j n} / x_{i j}=m_{j i n} / m_{j i} ; \operatorname{TSA3}=\frac{1}{N} \sum_{n=1}^{N}\left|s_{i j n}-s_{j i n}\right|$; and $\operatorname{TSC} 2=\frac{\sum_{n=1}^{N} s_{i j n} s_{j i n}}{\sqrt{\sum_{n=1}^{N} s_{i j n}^{2}} \sqrt{\sum_{n=1}^{N} s_{j i n}^{2}}}$. 


\section{Appendix B: Estimation without Country Fixed Effects}

Tables A-1 and A-2 present results of the EBA without country fixed effects. The main findings of the paper are not changed by removal of the country fixed effects. 
Table A-1: EBA Without Country Fixed Effects

Gravity Variables Not Included as I-variables

\begin{tabular}{|c|c|c|c|c|c|c|c|c|c|c|}
\hline Variable & Bound & $\beta$ & $\begin{array}{c}\text { Std. } \\
\text { Error }\end{array}$ & $\mathbf{t}$ & \# Obs. & R-sq & & Z-Variables & & $\begin{array}{c}\text { Robust/ } \\
\text { Fragile }\end{array}$ \\
\hline \multicolumn{11}{|c|}{ Bilateral Trade } \\
\hline BT1 & High & 3.94 & 0.29 & 13.77 & 4748 & 0.04 & $\mathrm{CU}$ & LANG & MINTL & robust \\
\hline BT1 & Base & 3.50 & 0.27 & 13.20 & 4948 & 0.03 & & & & \\
\hline BT1 & Low & 1.69 & 0.38 & 4.43 & 1107 & 0.14 & ISA2 & TSA3 & IND & \\
\hline BT2 & High & 16.79 & 2.01 & 8.35 & 2623 & 0.04 & ISC1 & MAXL & ADJ & robust \\
\hline BT2 & Base & 13.49 & 1.07 & 12.57 & 4948 & 0.03 & & & & \\
\hline BT2 & Low & 5.41 & 1.25 & 4.33 & 3736 & 0.11 & MINED & ADJ & IND & \\
\hline ВT3 & High & 4.13 & 0.40 & 10.30 & 3155 & 0.05 & ISC1 & ADJ & MINPOP & robust \\
\hline BT3 & Base & 4.30 & 0.28 & 15.37 & 5884 & 0.04 & & & & \\
\hline BT3 & Low & 1.76 & 0.33 & 5.31 & 2696 & 0.14 & ISA2 & MINED & IND & \\
\hline BT4 & High & 7.78 & 0.82 & 9.54 & 3076 & 0.04 & ISC1 & MAXL & MINPOP & robust \\
\hline BT4 & Base & 7.09 & 0.47 & 15.05 & 5884 & 0.04 & & & & \\
\hline BT4 & Low & 3.71 & 0.71 & 5.21 & 2551 & 0.11 & ISA2 & MINED & IND & \\
\hline \multicolumn{11}{|l|}{ Total Trade } \\
\hline TT1 & High & 0.18 & 0.05 & 3.52 & 1107 & 0.08 & ISA2 & TSA3 & MAXGDP & fragile \\
\hline TT1 & Base & 0.11 & 0.02 & 4.58 & 4948 & 0.00 & & & & \\
\hline TT1 & Low & -0.06 & 0.05 & -1.07 & 1687 & 0.02 & TSS3 & MAXED & MINL & \\
\hline TT2 & High & 0.13 & 0.02 & 7.55 & 1516 & 0.10 & ISC2 & TSC3 & MAXGDP & fragile \\
\hline TT2 & Base & 0.05 & 0.01 & 5.68 & 5884 & 0.01 & & & & \\
\hline TT2 & Low & -0.03 & 0.02 & -1.40 & 1989 & 0.11 & TSS3 & MINL & IND & \\
\hline \multicolumn{11}{|c|}{ Industrial Similarity } \\
\hline ISC1 & High & 0.47 & 0.05 & 9.18 & 1060 & 0.10 & TSC3 & MAXED & MAXGDP & fragile \\
\hline ISC1 & Base & 0.17 & 0.03 & 6.52 & 3238 & 0.01 & & & & \\
\hline ISC1 & Low & -0.01 & 0.06 & -0.24 & 957 & 0.16 & ISC2 & TSC3 & MINK & \\
\hline ISC2 & High & 0.47 & 0.04 & 11.77 & 1516 & 0.10 & TT2 & TSC3 & MAXGDP & fragile \\
\hline ISC2 & Base & 0.23 & 0.02 & 9.16 & 3401 & 0.02 & & & & \\
\hline ISC2 & Low & 0.05 & 0.05 & 1.05 & 1296 & 0.17 & TSC3 & MINED & IND & \\
\hline ISS1 & High & 0.06 & 0.04 & 1.36 & 2011 & 0.11 & BT1 & ISS2 & MINK & fragile \\
\hline ISS1 & Base & -0.24 & 0.03 & -7.43 & 3238 & 0.02 & & & & \\
\hline ISS1 & Low & -0.61 & 0.06 & -9.43 & 992 & 0.10 & TSS3 & MAXED & MAXL & \\
\hline ISS2 & High & -0.05 & 0.06 & -0.96 & 1296 & 0.17 & TSS3 & MINED & IND & fragile \\
\hline ISS2 & Base & -0.30 & 0.03 & -10.47 & 3401 & 0.03 & & & & \\
\hline ISS2 & Low & -0.53 & 0.05 & -11.28 & 1516 & 0.10 & TT2 & TSS3 & MAXGDP & \\
\hline
\end{tabular}


Table A-1: EBA Without Country Fixed Effects

Gravity Variables Not Included as I-variables

\begin{tabular}{|c|c|c|c|c|c|c|c|c|c|c|}
\hline Variable & Bound & $\beta$ & $\begin{array}{c}\text { Std. } \\
\text { Error }\end{array}$ & $\mathrm{t}$ & \# Obs. & R-sq & & Z-Variables & & $\begin{array}{l}\text { Robust/ } \\
\text { Fragile }\end{array}$ \\
\hline ISA1 & High & 0.03 & 0.02 & 1.13 & 2011 & 0.11 & BT1 & ISA2 & MINK & fragile \\
\hline ISA1 & Base & -0.14 & 0.02 & -7.63 & 3238 & 0.02 & & & & \\
\hline ISA1 & Low & -0.34 & 0.03 & -10.20 & 1060 & 0.11 & TSA2 & TSA3 & MAXED & \\
\hline ISA2 & High & -0.05 & 0.03 & -1.55 & 1296 & 0.17 & TSA3 & MINED & IND & fragile \\
\hline ISA2 & Base & -0.18 & 0.02 & -11.35 & 3401 & 0.04 & & & & \\
\hline ISA2 & Low & -0.30 & 0.03 & -11.65 & 1518 & 0.09 & TSA3 & MAXGDP & MINPOP & \\
\hline \multicolumn{11}{|c|}{ Trade Similarity } \\
\hline TSC1 & High & 0.20 & 0.02 & 7.85 & 1828 & 0.05 & TSC3 & MAXED & MAXK & fragile \\
\hline TSC1 & Base & -0.02 & 0.01 & -1.54 & 3817 & 0.00 & & & & \\
\hline TSC1 & Low & -0.09 & 0.02 & -4.57 & 1641 & 0.06 & ISC1 & ISC2 & MINPOP & \\
\hline TSC2 & High & 0.17 & 0.05 & 3.35 & 1828 & 0.03 & TSC3 & MAXED & MAXGDP & fragile \\
\hline TSC2 & Base & -0.06 & 0.03 & -2.08 & 3895 & 0.00 & & & & \\
\hline TSC2 & Low & -0.18 & 0.05 & -3.95 & 1678 & 0.05 & ISC1 & ISC2 & MINPOP & \\
\hline TSC3 & High & 0.04 & 0.02 & 1.81 & 1296 & 0.12 & ISC2 & MINED & MAXGDP & fragile \\
\hline TSC3 & Base & -0.06 & 0.02 & -3.55 & 2174 & 0.01 & & & & \\
\hline TSC3 & Low & -0.08 & 0.02 & -3.86 & 1107 & 0.05 & TT1 & ISC1 & TSC1 & \\
\hline TSS1 & High & 0.13 & 0.03 & 4.58 & 1641 & 0.07 & ISS1 & ISS2 & MINTL & fragile \\
\hline TSS1 & Base & 0.00 & 0.02 & 0.06 & 3817 & 0.00 & & & & \\
\hline TSS1 & Low & -0.20 & 0.03 & -6.00 & 1828 & 0.04 & TSS3 & MAXED & MAXGDP & \\
\hline TSS2 & High & 0.51 & 0.08 & 6.48 & 1678 & 0.07 & ISS1 & ISS2 & MINPOP & fragile \\
\hline TSS2 & Base & 0.19 & 0.05 & 3.87 & 3895 & 0.00 & & & & \\
\hline TSS2 & Low & -0.31 & 0.09 & -3.49 & 1828 & 0.03 & TSS3 & MAXED & MAXGDP & \\
\hline TSS3 & High & 0.07 & 0.03 & 2.19 & 891 & 0.11 & BT2 & ISS1 & ISS2 & fragile \\
\hline TSS3 & Base & -0.03 & 0.02 & -1.51 & 2174 & 0.00 & & & & \\
\hline TSS3 & Low & -0.06 & 0.02 & -2.61 & 1769 & 0.03 & TT1 & MAXED & MAXGDP & \\
\hline TSA1 & High & 0.09 & 0.01 & 6.90 & 1641 & 0.09 & ISA1 & ISA2 & MINPOP & fragile \\
\hline TSA1 & Base & 0.04 & 0.01 & 4.66 & 3817 & 0.01 & & & & \\
\hline TSA1 & Low & -0.09 & 0.02 & -5.29 & 1828 & 0.04 & TSA3 & MAXED & MAXGDP & \\
\hline TSA2 & High & 0.23 & 0.03 & 8.35 & 1678 & 0.09 & ISA1 & ISA2 & MINPOP & fragile \\
\hline TSA2 & Base & 0.14 & 0.02 & 7.35 & 3895 & 0.01 & & & & \\
\hline TSA2 & Low & -0.10 & 0.04 & -2.63 & 1828 & 0.03 & TSA3 & MAXED & MAXGDP & \\
\hline TSA3 & High & 0.07 & 0.02 & 4.08 & 1038 & 0.06 & TT1 & ISA1 & MAXL & fragile \\
\hline TSA3 & Base & 0.06 & 0.01 & 4.69 & 2174 & 0.01 & & & & \\
\hline TSA3 & Low & -0.02 & 0.02 & -1.06 & 1296 & 0.12 & ISA2 & MINED & MAXGDP & \\
\hline
\end{tabular}


Table A-1: EBA Without Country Fixed Effects

Gravity Variables Not Included as I-variables

\begin{tabular}{|c|c|c|c|c|c|c|c|c|c|c|}
\hline Variable & Bound & $\beta$ & \begin{tabular}{|c|} 
Std. \\
Error
\end{tabular} & $\mathbf{t}$ & \# Obs. & R-sq & & Z-Variables & & $\begin{array}{l}\text { Robu } \\
\text { Fragi } \\
\end{array}$ \\
\hline \multicolumn{11}{|c|}{ Factor Endowments } \\
\hline MINED & High & 0.17 & 0.02 & 7.96 & 1013 & 0.12 & TT1 & ISC1 & TSC3 & fragile \\
\hline MINED & Base & 0.09 & 0.01 & 13.02 & 4093 & 0.04 & & & & \\
\hline MINED & Low & -0.03 & 0.02 & -1.68 & 1769 & 0.13 & BT2 & TSA3 & MINK & \\
\hline MAXED & High & 0.20 & 0.03 & 6.96 & 1227 & 0.09 & ISA2 & TSA3 & MAXL & fragile \\
\hline MAXED & Base & 0.08 & 0.01 & 7.55 & 4093 & 0.01 & & & & \\
\hline MAXED & Low & -0.02 & 0.02 & -0.96 & 2551 & 0.07 & ISC1 & MINED & DEV & \\
\hline MINK & High & 0.08 & 0.01 & 11.62 & 1296 & 0.16 & ISC2 & TSC3 & MAXED & fragile \\
\hline MINK & Base & 0.04 & 0.00 & 16.81 & 5776 & 0.05 & & & & \\
\hline MINK & Low & 0.01 & 0.01 & 1.79 & 2551 & 0.10 & ISS1 & MINED & IND & \\
\hline MAXK & High & 0.05 & 0.01 & 3.91 & 1518 & 0.08 & ISC2 & TSC3 & DEV & fragile \\
\hline MAXK & Base & 0.03 & 0.00 & 9.76 & 5776 & 0.02 & & & & \\
\hline MAXK & Low & -0.01 & 0.01 & -1.32 & 2163 & 0.08 & TSA3 & MINK & DEV & \\
\hline MINL & High & 0.00 & 0.00 & 1.08 & 3155 & 0.03 & TT2 & ISC2 & MAXL & fragile \\
\hline MINL & Base & -0.01 & 0.00 & -1.90 & 5563 & 0.00 & & & & \\
\hline MINL & Low & -0.02 & 0.01 & -3.01 & 1985 & 0.01 & TSS3 & DIST & MINTL & \\
\hline MAXL & High & 0.00 & 0.01 & 0.45 & 1985 & 0.01 & TSC3 & MINL & DIST & fragile \\
\hline MAXL & Base & 0.00 & 0.00 & -0.81 & 5563 & 0.00 & & & & \\
\hline MAXL & Low & -0.03 & 0.01 & -4.28 & 1991 & 0.12 & TSS3 & MAXTL & IND & \\
\hline \multicolumn{11}{|l|}{ Currency Union } \\
\hline CU & High & 0.15 & 0.07 & 2.29 & 1192 & 0.11 & ISC1 & TSC3 & MINK & fragile \\
\hline CU & Base & -0.02 & 0.03 & -0.95 & 5993 & 0.00 & & & & \\
\hline $\mathrm{CU}$ & Low & -0.28 & 0.12 & -2.37 & 2273 & 0.08 & TT1 & ISA1 & MINED & \\
\hline \multicolumn{11}{|c|}{ Gravity Variables } \\
\hline \multirow[t]{3}{*}{ ADJ } & High & 0.25 & 0.04 & 6.71 & 1828 & 0.04 & TSA3 & MAXED & DEV & fragile \\
\hline & Base & 0.19 & 0.03 & 6.98 & 5776 & 0.01 & & & & \\
\hline & Low & -0.03 & 0.05 & -0.50 & 2011 & 0.06 & BT2 & ISA1 & ISA2 & \\
\hline \multirow[t]{3}{*}{ LANG } & High & 0.02 & 0.02 & 1.31 & 1192 & 0.07 & ISS1 & TSS3 & DEV & fragile \\
\hline & Base & 0.01 & 0.01 & 1.35 & 5776 & 0.00 & & & & \\
\hline & Low & -0.05 & 0.02 & -2.90 & 1439 & 0.08 & BT1 & ISC2 & TSC3 & \\
\hline \multirow[t]{3}{*}{ DIST } & High & 0.00 & 0.00 & 0.98 & 1516 & 0.10 & ВT3 & ISC2 & TSC3 & fragile \\
\hline & Base & 0.00 & 0.00 & -4.41 & 5776 & 0.00 & & & & \\
\hline & Low & 0.00 & 0.00 & -4.48 & 1060 & 0.12 & ISS1 & TSS3 & MAXED & \\
\hline
\end{tabular}


Table A-1: EBA Without Country Fixed Effects

Gravity Variables Not Included as I-variables

\begin{tabular}{clrrrrrrrrrr}
\hline Variable & Bound & \multicolumn{1}{c}{$\begin{array}{c}\text { Std. } \\
\text { Error }\end{array}$} & \multicolumn{1}{c}{ t } & \# Obs. & R-sq & & Z-Variables & Robust/ \\
Fragile
\end{tabular}


Table A-2: EBA Without Country Fixed Effects

Gravity Variables Included as I-variables

\begin{tabular}{|c|c|c|c|c|c|c|c|c|c|}
\hline Variable & Bound & $\beta$ & $\begin{array}{c}\text { Std. } \\
\text { Error }\end{array}$ & $\mathbf{t}$ & R-sq & & Z-Variables & & $\begin{array}{l}\text { Robust/ } \\
\text { Fragile }\end{array}$ \\
\hline \multicolumn{10}{|c|}{ Bilateral Trade } \\
\hline \multirow[t]{3}{*}{ BT1 } & High & 1.62 & 0.40 & 4.04 & 0.09 & TT1 & ISC1 & CU & robust \\
\hline & Base & 1.70 & 0.33 & 5.20 & 0.09 & & & & \\
\hline & Low & 1.09 & 0.45 & 2.40 & 0.15 & ISA1 & TSA3 & MINL & \\
\hline \multirow[t]{3}{*}{ ВT2 } & High & 6.15 & 2.27 & 2.71 & 0.07 & ISC1 & MINL & CU & fragile \\
\hline & Base & 5.87 & 1.23 & 4.77 & 0.09 & & & & \\
\hline & Low & 3.99 & 2.32 & 1.72 & 0.11 & ISA1 & MINED & MAXL & \\
\hline \multirow[t]{3}{*}{ ВТ3 } & High & 2.32 & 0.45 & 5.11 & 0.10 & TT2 & ISC1 & MAXED & robust \\
\hline & Base & 2.00 & 0.34 & 5.96 & 0.08 & & & & \\
\hline & Low & 1.35 & 0.40 & 3.35 & 0.19 & ISC2 & TSC3 & MINK & \\
\hline \multirow[t]{3}{*}{ BT4 } & High & 3.88 & 0.95 & 4.10 & 0.07 & ISC1 & MINL & $\mathrm{CU}$ & robust \\
\hline & Base & 3.33 & 0.54 & 6.17 & 0.09 & & & & \\
\hline & Low & 2.72 & 1.01 & 2.70 & 0.11 & ISA1 & ISA2 & MAXL & \\
\hline \multicolumn{10}{|l|}{ Total Trade } \\
\hline \multirow[t]{3}{*}{ TT1 } & High & -0.02 & 0.08 & -0.28 & 0.17 & ISA1 & ISA2 & TSA3 & fragile \\
\hline & Base & 0.03 & 0.03 & 1.08 & 0.09 & & & & \\
\hline & Low & -0.18 & 0.07 & -2.60 & 0.15 & TSA3 & MAXED & MINL & \\
\hline \multirow[t]{3}{*}{ TT2 } & High & 0.05 & 0.02 & 2.71 & 0.12 & ISC1 & ISC2 & MAXED & fragile \\
\hline & Base & 0.01 & 0.01 & 1.31 & 0.08 & & & & \\
\hline & Low & -0.06 & 0.03 & -2.31 & 0.15 & TSA3 & MAXED & MINL & \\
\hline \multicolumn{10}{|c|}{ Industrial Similarity } \\
\hline \multirow[t]{3}{*}{ ISC1 } & High & 0.34 & 0.06 & 6.11 & 0.17 & TSC3 & MAXED & MAXL & fragile \\
\hline & Base & 0.11 & 0.03 & 4.34 & 0.07 & & & & \\
\hline & Low & -0.06 & 0.03 & -1.60 & 0.13 & BT1 & ISC2 & MINK & \\
\hline \multirow[t]{3}{*}{ ISC2 } & High & 0.27 & 0.06 & 4.73 & 0.16 & TT2 & ISC1 & TSC3 & fragile \\
\hline & Base & 0.18 & 0.03 & 6.65 & 0.11 & & & & \\
\hline & Low & -0.03 & 0.05 & -0.52 & 0.20 & TSC3 & MINED & MINK & \\
\hline \multirow[t]{3}{*}{ ISS1 } & High & 0.07 & 0.05 & 1.55 & 0.13 & BT1 & ISS2 & MINK & fragile \\
\hline & Base & -0.16 & 0.03 & -4.91 & 0.08 & & & & \\
\hline & Low & -0.31 & 0.05 & -6.33 & 0.12 & TSS2 & MAXED & MAXL & \\
\hline \multirow[t]{3}{*}{ ISS2 } & High & 0.01 & 0.06 & 0.14 & 0.20 & TSS3 & MINED & MINK & fragile \\
\hline & Base & -0.22 & 0.03 & -6.98 & 0.11 & & & & \\
\hline & Low & -0.35 & 0.07 & -5.04 & 0.17 & ISS1 & TSS1 & TSS3 & \\
\hline ISA1 & High & 0.04 & 0.02 & 1.43 & 0.13 & BT1 & ISA2 & MINK & fragile \\
\hline
\end{tabular}


Table A-2: EBA Without Country Fixed Effects

Gravity Variables Included as I-variables

\begin{tabular}{rllcccccccc}
\hline Variable & Bound & $\boldsymbol{\beta}$ & Etd. & Error & t & R-sq & & Z-Variables & & Robust/ \\
Fragile
\end{tabular}

Trade Similarity

\begin{tabular}{|c|c|c|c|c|c|c|c|c|c|}
\hline \multirow[t]{3}{*}{ TSC1 } & High & 0.10 & 0.03 & 4.18 & 0.16 & TSC3 & MAXED & MAXL & \multirow[t]{3}{*}{ fragile } \\
\hline & Base & -0.01 & 0.01 & -0.59 & 0.10 & & & & \\
\hline & Low & -0.04 & 0.02 & -2.06 & 0.14 & BT3 & ISC1 & ISC2 & \\
\hline \multirow[t]{3}{*}{ TSC2 } & High & 0.13 & 0.05 & 2.60 & 0.15 & TSC3 & MAXED & MINL & \multirow[t]{3}{*}{ fragile } \\
\hline & Base & -0.01 & 0.03 & -0.44 & 0.10 & & & & \\
\hline & Low & -0.10 & 0.07 & -1.47 & 0.17 & ISC1 & ISC2 & TSC3 & \\
\hline \multirow[t]{3}{*}{ TSC3 } & High & 0.03 & 0.02 & 1.32 & 0.20 & ISC2 & MINED & MINK & \multirow[t]{3}{*}{ fragile } \\
\hline & Base & -0.02 & 0.02 & -1.52 & 0.13 & & & & \\
\hline & Low & -0.02 & 0.02 & -0.86 & 0.18 & ВT3 & TSC1 & MAXED & \\
\hline \multirow[t]{3}{*}{ TSS1 } & High & 0.12 & 0.04 & 2.65 & 0.17 & ISS1 & ISS2 & TSS3 & \multirow[t]{3}{*}{ fragile } \\
\hline & Base & 0.00 & 0.02 & -0.25 & 0.10 & & & & \\
\hline & Low & -0.11 & 0.03 & -3.17 & 0.15 & TSS3 & MAXED & MAXL & \\
\hline \multirow[t]{3}{*}{ TSS2 } & High & 0.23 & 0.11 & 2.07 & 0.17 & ISS1 & ISS2 & TSS3 & \multirow[t]{3}{*}{ fragile } \\
\hline & Base & 0.05 & 0.05 & 0.90 & 0.10 & & & & \\
\hline & Low & -0.22 & 0.08 & -2.64 & 0.18 & TSS3 & MINED & MINK & \\
\hline \multirow[t]{3}{*}{ TSS3 } & High & 0.08 & 0.03 & 2.55 & 0.17 & BT2 & ISS1 & ISS2 & \multirow[t]{3}{*}{ fragile } \\
\hline & Base & 0.02 & 0.02 & 1.09 & 0.13 & & & & \\
\hline & Low & 0.01 & 0.03 & 0.37 & 0.18 & TT2 & ISS2 & MINED & \\
\hline \multirow[t]{3}{*}{ TSA1 } & High & 0.04 & 0.02 & 1.50 & 0.17 & ISA1 & ISA2 & TSA3 & \multirow[t]{3}{*}{ fragile } \\
\hline & Base & 0.01 & 0.01 & 1.08 & 0.10 & & & & \\
\hline & Low & -0.04 & 0.02 & -2.50 & 0.15 & TSA3 & MAXED & MINL & \\
\hline \multirow[t]{3}{*}{ TSA2 } & High & 0.08 & 0.05 & 1.77 & 0.17 & ISA1 & ISA2 & MAXK & \multirow[t]{3}{*}{ fragile } \\
\hline & Base & 0.05 & 0.02 & 2.30 & 0.10 & & & & \\
\hline & Low & -0.09 & 0.04 & -2.54 & 0.15 & TSA3 & MAXED & MINL & \\
\hline \multirow[t]{3}{*}{ TSA3 } & High & 0.03 & 0.02 & 1.75 & 0.16 & ISA1 & ISA2 & MINL & \multirow[t]{3}{*}{ fragile } \\
\hline & Base & 0.02 & 0.01 & 1.82 & 0.14 & & & & \\
\hline & Low & -0.01 & 0.02 & -0.83 & 0.20 & ISA2 & MINED & MINK & \\
\hline
\end{tabular}


Table A-2: EBA Without Country Fixed Effects

Gravity Variables Included as I-variables

\begin{tabular}{|c|c|c|c|c|c|c|c|c|c|}
\hline Variable & Bound & $\beta$ & $\begin{array}{c}\text { Std. } \\
\text { Error }\end{array}$ & $\mathbf{t}$ & R-sq & & Z-Variables & & $\begin{array}{c}\text { Robust/ } \\
\text { Fragile }\end{array}$ \\
\hline \multicolumn{10}{|c|}{ Factor Endowments } \\
\hline \multirow[t]{3}{*}{ MINED } & High & 0.13 & 0.02 & 5.17 & 0.20 & ISC1 & ISC2 & TSC3 & fragile \\
\hline & Base & 0.05 & 0.01 & 6.50 & 0.11 & & & & \\
\hline & Low & -0.05 & 0.02 & -2.42 & 0.18 & BT2 & TSA3 & MINK & \\
\hline \multirow[t]{3}{*}{ MAXED } & High & 0.13 & 0.04 & 3.17 & 0.17 & ISS1 & TSS3 & MAXL & fragile \\
\hline & Base & 0.02 & 0.01 & 1.19 & 0.10 & & & & \\
\hline & Low & -0.01 & 0.03 & -0.22 & 0.16 & TSA3 & MINED & MAXK & \\
\hline \multirow[t]{3}{*}{ MINK } & High & 0.06 & 0.01 & 7.09 & 0.20 & ISC2 & TSC3 & MAXED & fragile \\
\hline & Base & 0.02 & 0.00 & 7.95 & 0.09 & & & & \\
\hline & Low & 0.01 & 0.01 & 0.95 & 0.10 & ISA1 & MINED & MINL & \\
\hline \multirow[t]{3}{*}{ MAXK } & High & 0.01 & 0.02 & 0.59 & 0.18 & ISS2 & TSS3 & MAXED & fragile \\
\hline & Base & 0.01 & 0.00 & 2.74 & 0.08 & & & & \\
\hline & Low & -0.04 & 0.02 & -2.10 & 0.16 & ISC1 & TSC3 & MINK & \\
\hline \multirow[t]{3}{*}{ MINL } & High & -0.01 & 0.01 & -0.99 & 0.16 & BT4 & ISC2 & TSC3 & fragile \\
\hline & Base & -0.01 & 0.00 & -3.07 & 0.07 & & & & \\
\hline & Low & -0.03 & 0.01 & -3.91 & 0.15 & TT2 & TSS3 & MAXED & \\
\hline \multirow[t]{3}{*}{ MAXL } & High & -0.02 & 0.01 & -2.23 & 0.10 & ISA1 & TSA2 & MINL & robust \\
\hline & Base & -0.03 & 0.01 & -4.41 & 0.07 & & & & \\
\hline & Low & -0.05 & 0.01 & -4.13 & 0.17 & ISA2 & TSA3 & MAXED & \\
\hline \multicolumn{10}{|c|}{ Currency Union } \\
\hline \multirow[t]{3}{*}{$\mathrm{CU}$} & High & -0.10 & 0.10 & -1.01 & 0.17 & ISC1 & TSC3 & MINK & fragile \\
\hline & Base & -0.03 & 0.03 & -0.97 & 0.08 & & & & \\
\hline & Low & -0.30 & 0.12 & -2.54 & 0.10 & TT1 & ISS1 & MAXED & \\
\hline
\end{tabular}




\section{References}

Alvarez, F. and R. E. Lucas, Jr., 2004, General equilibrium analysis of the Eaton-Kortum Model of international trade, manuscript, University of Chicago, April 2004.

Baxter, M., 1992, Fiscal policy, specialization, and trade in the two-sector model: The return of Ricardo? Journal of Political Economy 100, 713-744.

, 1995, International trade and business cycles, in: G. Grossman and K.

Rogoff, eds., Handbook of International Economics, Vol. 3 (North-Holland, Amsterdam) 1801-1864.

Baxter, M. and R. King, 1999, Measuring business cycles: Approximate band-pass filters for economic time series, Review of Economics and Statistics 81, 585-593.

Calderon, C., A. Chong, and E. Stein, 2002, Trade intensity and business cycle synchronization: Are developing countries any different? Manuscript, Inter-American Development Bank, March 2002.

Canova, F. and H. Dellas, 1993, Trade interdependence and the international business cycle, Journal of International Economics 34, 23-47.

Clark, T. and K. Shin, 2000, The Sources of Fluctuations Within and Across Countries, in: G. Hess and E. van Wincoop, eds., Intranational Macroeconomics (Cambridge University Press, Boston, MA) 189-220.

Clark, T. and E. van Wincoop, 2001, Borders and business cycles, Journal of International Economics 55, 59-85.

Eaton, J. and S. Kortum, 2002, Technology, geography and trade, Econometrica 70, 1741-1779.

Fidrmuc, J., 2002, The endogeneity of the optimum currency area criteria, intra-industry trade, and EMU enlargement, manuscript, Austria National Bank, 2002.

Frankel, J. and A. Rose, 1998, The Endogeneity of the Optimum Currency Area Criteria, Economic Journal 108, 1009-1025. 
Frankel, J. and A. Rose, 2002, An estimate of the effect of common currencies on trade and income, Quarterly Journal of Economics 117, 437-466.

Gregory, A.and A. Head, 1999, Common and country-specific fluctuations in productivity, investment, and the current account, Journal of Monetary Economics 44, 423-451.

Gregory, A.and A. Head, and J. Raynauld, 1997, Measuring world business cycles, International Economic Review 38, 677-701.

Gruben, W., J. Koo and E. Millis, 2002, How much does international trade affect business cycle synchronization?, Federal Reserve Bank of Dallas, Research Department Working Paper 0203, August 2002.

Helpman, E. and P. Krugman, 1985, Market structure and foreign trade. (MIT Press, Cambridge MA) 1985.

Imbs, J., 1998, Fluctuations, bilateral trade and exchange rate regime, University of Lausanne, Working Paper.

, 1999, Co-fluctuations, manuscript, London Business School, June 1999. , 2003, Trade, finance, specialization and synchronization, forthcoming, Review of Economics and Statistics.

Kim, S., 1995, Expansion of markets and the geographic distribution of economic activities: The trends in U.S. regional manufacturing structure, 1860-1987, Quarterly Journal of Economics 110, 881-908.

Kose, M., C. Otrok and C. Whiteman, 2003, International businses cycles: World, region and country-specific factors, American Economic Review 93, 1216-1239.

Kose, M., E. Prasad, and M. Terrones, 2003, How does globalization affect the synchronization of business cycles? American Economic Review 93, 57-62.

Kose, M. and Yi, K., 2001, International trade and business ccles: Is vertical specialization the missing link? American Economic Review 91, 371-375. 
Kose, M. and Yi, K., 2004, The Trade-Comovement Problem in International Macroeconomics, Working Paper, International Monetary Fund.

Leamer, E., 1983, Let’s Take the Con Out of Econometrics, American Economic Review 73, 31-43.

Levine, R. and D., 1992, A sensitivity analysis of cross-country growth regressions, American Economic Review 82, 942-963.

Lumsdaine, R. and E. Prasad, 2003, Identifying the common component in international economic fluctuations, Economic Journal 113, 101-127.

Mundell, R., 1961, A theory of optimum currency areas, American Economic Review 51, 657665.

Norrbin, S. and D. Schlagenhauf, 1996, The role of international factors in the business cycle: A multicountry study, Journal of International Economics 40, 85-104.

Otto, G., G. Voss and L. Willard, 2003, A cross section study of the international transmission of business cycles, manuscript, University of New South Wales, June 2003.

Rose, A. and C. Engel, 2002, Currency unions and international integration, Journal of Money, Credit and Banking 34, 1067-1089.

Shea, J., 1996, Comovements in cities, Carnegie Rochester Conference Series on Public Policy 44, 169-206.

Shin, K. and Y. Wang, 2003, Trade integration and business cycle synchronization in East Asia, Working Paper, Korea University. 
Stockman, Alan, 1988, Sectoral and aggregate national disturbances to industrial output in seven European countries, Journal of Monetary Economics 21, 387-409. 
Table 1: Variable Correlation Matrix

\begin{tabular}{|c|c|c|c|c|c|c|c|c|c|c|c|c|c|c|c|c|c|c|c|c|c|c|}
\hline Variable & \begin{tabular}{|c|} 
Business \\
Cycle
\end{tabular} & BT1 & BT2 & BT3 & BT4 & TT1 & TT2 & ISS1 & ISA1 & ISC1 & ISS2 & ISA2 & ISC2 & TSS1 & TSA1 & TSC1 & TSS2 & TSA2 & TSC2 & TSS3 & TSA3 & TSC3 \\
\hline \multicolumn{23}{|c|}{ Bilateral Trade Intensity } \\
\hline BT1 & 0.18 & 1 & 0.81 & 0.76 & 0.64 & 0.00 & 0.03 & 0.12 & 0.14 & 0.11 & 0.18 & 0.19 & 0.16 & -0.02 & -0.10 & 0.01 & -0.14 & -0.19 & -0.08 & 0.12 & -0.07 & -0.04 \\
\hline BT2 & 0.18 & 0.81 & 1 & 0.64 & 0.87 & 0.12 & 0.12 & 0.11 & 0.12 & 0.09 & 0.14 & 0.15 & 0.13 & -0.01 & -0.08 & 0.00 & -0.09 & -0.13 & -0.05 & 0.12 & -0.04 & -0.02 \\
\hline BT3 & 0.20 & 0.76 & 0.64 & 1 & 0.76 & -0.01 & 0.03 & 0.15 & 0.16 & 0.13 & 0.22 & 0.23 & 0.19 & 0.01 & -0.09 & 0.01 & -0.16 & -0.23 & -0.10 & 0.13 & -0.11 & -0.07 \\
\hline BT4 & 0.19 & 0.64 & 0.87 & 0.76 & 1 & 0.12 & 0.14 & 0.14 & 0.15 & 0.12 & 0.15 & 0.16 & 0.14 & 0.03 & -0.07 & 0.01 & -0.09 & -0.15 & -0.05 & 0.12 & -0.07 & -0.04 \\
\hline \multicolumn{23}{|c|}{ Total Trade Intensity } \\
\hline TT1 & 0.06 & 0.00 & 0.12 & -0.01 & 0.12 & 1 & 0.86 & -0.11 & -0.11 & -0.11 & -0.24 & -0.23 & -0.25 & -0.11 & -0.15 & -0.20 & -0.02 & -0.05 & 0.01 & -0.04 & 0.00 & 0.07 \\
\hline TT2 & 0.07 & 0.03 & 0.12 & 0.03 & 0.14 & 0.86 & 1 & -0.10 & -0.10 & -0.10 & -0.24 & -0.24 & -0.28 & -0.12 & -0.21 & -0.23 & -0.08 & -0.14 & -0.05 & -0.04 & -0.01 & 0.05 \\
\hline \multicolumn{23}{|c|}{ Similarity of Industrial Structure } \\
\hline ISS1 & 0.13 & 0.12 & 0.11 & 0.15 & 0.14 & -0.11 & -0.10 & 1 & 0.98 & 0.97 & 0.29 & 0.29 & 0.26 & 0.23 & 0.14 & 0.21 & 0.04 & 0.03 & 0.05 & 0.08 & -0.06 & -0.03 \\
\hline ISA1 & 0.13 & 0.14 & 0.12 & 0.16 & 0.15 & -0.11 & -0.10 & 0.98 & 1 & 0.96 & 0.29 & 0.30 & 0.27 & 0.22 & 0.13 & 0.22 & 0.05 & 0.03 & 0.06 & 0.08 & -0.07 & -0.03 \\
\hline ISC1 & 0.11 & 0.11 & 0.09 & 0.13 & 0.12 & -0.11 & -0.10 & 0.97 & 0.96 & 1 & 0.24 & 0.25 & 0.23 & 0.22 & 0.13 & 0.21 & 0.03 & 0.02 & 0.05 & 0.07 & -0.07 & -0.04 \\
\hline ISS2 & 0.18 & 0.18 & 0.14 & 0.22 & 0.15 & -0.24 & -0.24 & 0.29 & 0.29 & 0.24 & 1 & 0.97 & 0.95 & 0.23 & 0.15 & 0.25 & 0.07 & 0.01 & 0.08 & 0.24 & -0.04 & -0.09 \\
\hline ISA2 & 0.19 & 0.19 & 0.15 & 0.23 & 0.16 & -0.23 & -0.24 & 0.29 & 0.30 & 0.25 & 0.97 & 1 & 0.94 & 0.21 & 0.14 & 0.26 & 0.06 & 0.01 & 0.08 & 0.23 & -0.06 & -0.10 \\
\hline ISC2 & 0.16 & 0.16 & 0.13 & 0.19 & 0.14 & -0.25 & -0.28 & 0.26 & 0.27 & 0.23 & 0.95 & 0.94 & 1 & 0.24 & 0.20 & 0.31 & 0.11 & 0.07 & 0.11 & 0.24 & -0.04 & -0.08 \\
\hline \multicolumn{23}{|c|}{ Similarity of Trade Structure } \\
\hline TSS1 & 0.00 & -0.02 & -0.01 & 0.01 & 0.03 & -0.11 & -0.12 & 0.23 & 0.22 & 0.22 & 0.23 & 0.21 & 0.24 & 1 & 0.85 & 0.61 & 0.43 & 0.46 & 0.37 & 0.11 & 0.01 & 0.11 \\
\hline TSA1 & -0.08 & -0.10 & -0.08 & -0.09 & -0.07 & -0.15 & -0.21 & 0.14 & 0.13 & 0.13 & 0.15 & 0.14 & 0.20 & 0.85 & 1 & 0.71 & 0.57 & 0.71 & 0.43 & 0.12 & 0.23 & 0.38 \\
\hline TSC1 & -0.02 & 0.01 & 0.00 & 0.01 & 0.01 & -0.20 & -0.23 & 0.21 & 0.22 & 0.21 & 0.25 & 0.26 & 0.31 & 0.61 & 0.71 & 1 & 0.47 & 0.53 & 0.42 & 0.14 & 0.07 & 0.20 \\
\hline TSS2 & -0.06 & -0.14 & -0.09 & -0.16 & -0.09 & -0.02 & -0.08 & 0.04 & 0.05 & 0.03 & 0.07 & 0.06 & 0.11 & 0.43 & 0.57 & 0.47 & 1 & 0.92 & 0.79 & 0.03 & 0.11 & 0.20 \\
\hline TSA2 & -0.12 & -0.19 & -0.13 & -0.23 & -0.15 & -0.05 & -0.14 & 0.03 & 0.03 & 0.02 & 0.01 & 0.01 & 0.07 & 0.46 & 0.71 & 0.53 & 0.92 & 1 & 0.71 & 0.05 & 0.27 & 0.36 \\
\hline TSC2 & -0.03 & -0.08 & -0.05 & -0.10 & -0.05 & 0.01 & -0.05 & 0.05 & 0.06 & 0.05 & 0.08 & 0.08 & 0.11 & 0.37 & 0.43 & 0.42 & 0.79 & 0.71 & 1 & 0.03 & 0.07 & 0.12 \\
\hline TSS3 & 0.03 & 0.12 & 0.12 & 0.13 & 0.12 & -0.04 & -0.04 & 0.08 & 0.08 & 0.07 & 0.24 & 0.23 & 0.24 & 0.11 & 0.12 & 0.14 & 0.03 & 0.05 & 0.03 & 1 & 0.71 & 0.29 \\
\hline TSA3 & -0.10 & -0.07 & -0.04 & -0.11 & -0.07 & 0.00 & -0.01 & -0.06 & -0.07 & -0.07 & -0.04 & -0.06 & -0.04 & 0.01 & 0.23 & 0.07 & 0.11 & 0.27 & 0.07 & 0.71 & 1 & 0.66 \\
\hline TSC3 & -0.08 & -0.04 & -0.02 & -0.07 & -0.04 & 0.07 & 0.05 & -0.03 & -0.03 & -0.04 & -0.09 & -0.10 & -0.08 & 0.11 & 0.38 & 0.20 & 0.20 & 0.36 & 0.12 & 0.29 & 0.66 & 1 \\
\hline
\end{tabular}


Table 1: Variable Correlation Matrix, cont'd.

\begin{tabular}{|c|c|c|c|c|c|c|c|c|c|c|c|c|c|c|c|c|c|c|c|c|c|c|}
\hline Variable & & BT1 & BT2 & BT3 & BT4 & TT1 & TT2 & ISS1 & ISA1 & ISC1 & ISS2 & ISA2 & ISC2 & TSS1 & TSA1 & TSC1 & TSS2 & TSA2 & TSC2 & TSS3 & TSA3 & TSC3 \\
\hline \multicolumn{2}{|c|}{ Factor Endowments } & & & & & & & & & & & & & & & & & & & & & \\
\hline MINED & 0.20 & 0.19 & 0.17 & 0.22 & 0.21 & 0.12 & 0.19 & 0.35 & 0.37 & 0.32 & 0.25 & 0.28 & 0.21 & 0.01 & -0.17 & -0.05 & -0.09 & -0.21 & -0.05 & 0.06 & -0.22 & -0.21 \\
\hline MAXED & 0.12 & 0.12 & 0.10 & 0.13 & 0.12 & 0.28 & 0.35 & -0.04 & -0.03 & -0.05 & -0.04 & -0.05 & -0.12 & -0.15 & -0.33 & -0.26 & -0.19 & -0.31 & -0.13 & -0.02 & -0.18 & -0.15 \\
\hline MINK & 0.22 & 0.20 & 0.19 & 0.26 & 0.24 & 0.17 & 0.20 & 0.40 & 0.39 & 0.34 & 0.33 & 0.32 & 0.24 & 0.05 & -0.17 & -0.08 & -0.17 & -0.27 & -0.12 & 0.09 & -0.21 & -0.24 \\
\hline MAXK & 0.13 & 0.11 & 0.11 & 0.14 & 0.13 & 0.34 & 0.40 & -0.11 & -0.12 & -0.15 & -0.05 & -0.07 & -0.17 & -0.22 & -0.41 & -0.35 & -0.26 & -0.36 & -0.16 & 0.00 & -0.20 & -0.22 \\
\hline MINL & -0.03 & -0.02 & -0.07 & -0.06 & -0.13 & -0.42 & -0.56 & 0.05 & 0.06 & 0.04 & 0.20 & 0.21 & 0.18 & 0.02 & 0.10 & 0.11 & 0.11 & 0.16 & 0.13 & 0.03 & 0.06 & 0.01 \\
\hline MAXL & -0.01 & 0.01 & -0.03 & -0.02 & -0.09 & -0.11 & -0.14 & 0.08 & 0.08 & 0.06 & 0.10 & 0.08 & 0.07 & 0.01 & 0.03 & 0.04 & 0.01 & 0.03 & 0.06 & 0.03 & 0.00 & 0.00 \\
\hline \multicolumn{23}{|l|}{ Gravity variables } \\
\hline ADJ & 0.09 & 0.34 & 0.31 & 0.38 & 0.30 & -0.03 & -0.03 & 0.07 & 0.07 & 0.06 & 0.09 & 0.10 & 0.08 & 0.00 & -0.01 & 0.02 & -0.07 & -0.08 & -0.04 & 0.09 & 0.02 & 0.01 \\
\hline LANG & 0.02 & 0.12 & 0.10 & 0.08 & 0.05 & -0.04 & -0.08 & 0.02 & 0.02 & 0.02 & 0.03 & 0.04 & 0.05 & -0.05 & -0.02 & 0.00 & -0.06 & -0.06 & -0.02 & 0.02 & 0.00 & 0.01 \\
\hline DIST & -0.06 & -0.19 & -0.18 & -0.20 & -0.17 & -0.02 & 0.06 & 0.04 & 0.03 & 0.03 & -0.11 & -0.11 & -0.10 & 0.12 & 0.10 & 0.04 & 0.08 & 0.10 & 0.06 & -0.12 & -0.01 & 0.02 \\
\hline MINPOP & 0.04 & 0.17 & 0.10 & 0.20 & 0.11 & -0.17 & -0.06 & 0.02 & 0.04 & 0.02 & 0.31 & 0.33 & 0.23 & -0.11 & -0.21 & -0.10 & -0.17 & -0.24 & -0.07 & 0.01 & -0.19 & -0.24 \\
\hline MAXPOP & 0.02 & 0.11 & 0.02 & 0.16 & 0.05 & -0.48 & -0.29 & 0.00 & 0.00 & -0.01 & 0.09 & 0.08 & 0.00 & -0.10 & -0.21 & -0.10 & -0.28 & -0.35 & -0.23 & -0.05 & -0.19 & -0.23 \\
\hline MINTL & 0.00 & 0.06 & -0.01 & 0.05 & -0.04 & -0.39 & -0.38 & 0.05 & 0.06 & 0.04 & 0.30 & 0.28 & 0.22 & -0.05 & -0.03 & -0.02 & -0.04 & -0.03 & 0.02 & 0.02 & -0.03 & -0.11 \\
\hline MAXTL & 0.02 & 0.06 & -0.03 & 0.07 & -0.04 & -0.42 & -0.35 & 0.00 & 0.00 & -0.03 & 0.16 & 0.13 & 0.09 & -0.03 & -0.06 & -0.03 & -0.21 & -0.21 & -0.13 & -0.02 & -0.10 & -0.14 \\
\hline IND & 0.25 & 0.34 & 0.32 & 0.37 & 0.35 & 0.07 & 0.09 & 0.23 & 0.26 & 0.20 & 0.28 & 0.29 & 0.24 & 0.05 & -0.07 & 0.04 & -0.06 & -0.14 & -0.02 & 0.14 & -0.13 & -0.09 \\
\hline DEV & -0.14 & -0.13 & -0.11 & -0.14 & -0.13 & -0.23 & -0.31 & 0.01 & 0.01 & 0.01 & 0.00 & 0.02 & 0.10 & 0.27 & 0.45 & 0.33 & 0.25 & 0.37 & 0.14 & -0.01 & 0.18 & 0.21 \\
\hline \multicolumn{23}{|l|}{ Currency Union } \\
\hline $\mathrm{CU}$ & -0.01 & 0.04 & 0.03 & 0.00 & -0.01 & 0.00 & -0.06 & 0.00 & 0.01 & 0.00 & 0.05 & 0.05 & 0.07 & 0.01 & 0.04 & -0.01 & -0.02 & 0.01 & 0.01 & 0.02 & 0.05 & 0.03 \\
\hline
\end{tabular}


Table 1: Variable Correlation Matrix, cont'd.

\begin{tabular}{|c|c|c|c|c|c|c|c|c|c|c|c|c|c|c|c|c|}
\hline \multirow{2}{*}{\multicolumn{2}{|c|}{$\begin{array}{ll}\text { Variable } & \text { MINEDN } \\
\text { Bilateral Trade Intensity }\end{array}$}} & AXXED & MINK & \multirow{2}{*}{ MAXK } & \multirow{2}{*}{ MINL } & \multirow{2}{*}{ MAXL } & \multirow[t]{2}{*}{ ADJ } & \multirow[t]{2}{*}{ LANG } & \multirow[t]{2}{*}{ DIST } & \multicolumn{4}{|c|}{ MINPOHИAXPOIMINTL MINTL } & \multirow[t]{2}{*}{ IND } & \multirow[t]{2}{*}{ DEV } & \multirow[t]{2}{*}{$\mathbf{C U}$} \\
\hline & & & & & & & & & & & & & & & & \\
\hline BT1 & 0.19 & 0.12 & 0.20 & 0.11 & -0.02 & 0.01 & 0.34 & 0.12 & -0.19 & 0.17 & 0.11 & 0.06 & 0.06 & 0.34 & -0.13 & 0.04 \\
\hline BT2 & 0.17 & 0.10 & 0.19 & 0.11 & -0.07 & -0.03 & 0.31 & 0.10 & -0.18 & 0.10 & 0.02 & -0.01 & -0.03 & 0.32 & -0.11 & 0.03 \\
\hline BT3 & 0.22 & 0.13 & 0.26 & 0.14 & -0.06 & -0.02 & 0.38 & 0.08 & -0.20 & 0.20 & 0.16 & 0.05 & 0.07 & 0.37 & -0.14 & 0.00 \\
\hline BT4 & 0.21 & 0.12 & 0.24 & 0.13 & -0.13 & -0.09 & 0.30 & 0.05 & -0.17 & 0.11 & 0.05 & -0.04 & -0.04 & 0.35 & -0.13 & -0.01 \\
\hline \multicolumn{17}{|c|}{ Total Trade Intensity } \\
\hline TT1 & 0.12 & 0.28 & 0.17 & 0.34 & -0.42 & -0.11 & -0.03 & -0.04 & -0.02 & -0.17 & -0.48 & -0.39 & -0.42 & 0.07 & -0.23 & 0.00 \\
\hline TT2 & 0.19 & 0.35 & 0.20 & 0.40 & -0.56 & -0.14 & -0.03 & -0.08 & 0.06 & -0.06 & -0.29 & -0.38 & -0.35 & 0.09 & -0.31 & -0.06 \\
\hline \multicolumn{17}{|c|}{ Similarity of Industrial Structure } \\
\hline ISS1 & 0.35 & -0.04 & 0.40 & -0.11 & 0.05 & 0.08 & 0.07 & 0.02 & 0.04 & 0.02 & 0.00 & 0.05 & 0.00 & 0.23 & 0.01 & 0.00 \\
\hline ISA1 & 0.37 & -0.03 & 0.39 & -0.12 & 0.06 & 0.08 & 0.07 & 0.02 & 0.03 & 0.04 & 0.00 & 0.06 & 0.00 & 0.26 & 0.01 & 0.01 \\
\hline ISC1 & 0.32 & -0.05 & 0.34 & -0.15 & 0.04 & 0.06 & 0.06 & 0.02 & 0.03 & 0.02 & -0.01 & 0.04 & -0.03 & 0.20 & 0.01 & 0.00 \\
\hline ISS2 & 0.25 & -0.04 & 0.33 & -0.05 & 0.20 & 0.10 & 0.09 & 0.03 & -0.11 & 0.31 & 0.09 & 0.30 & 0.16 & 0.28 & 0.00 & 0.05 \\
\hline ISA2 & 0.28 & -0.05 & 0.32 & -0.07 & 0.21 & 0.08 & 0.10 & 0.04 & -0.11 & 0.33 & 0.08 & 0.28 & 0.13 & 0.29 & 0.02 & 0.05 \\
\hline ISC2 & 0.21 & -0.12 & 0.24 & -0.17 & 0.18 & 0.07 & 0.08 & 0.05 & -0.10 & 0.23 & 0.00 & 0.22 & 0.09 & 0.24 & 0.10 & 0.07 \\
\hline \multicolumn{17}{|c|}{ Similarity of Trade Structure } \\
\hline TSS1 & 0.01 & -0.15 & 0.05 & -0.22 & 0.02 & 0.01 & 0.00 & -0.05 & 0.12 & -0.11 & -0.10 & -0.05 & -0.03 & 0.05 & 0.27 & 0.01 \\
\hline TSA1 & -0.17 & -0.33 & -0.17 & -0.41 & 0.10 & 0.03 & -0.01 & -0.02 & 0.10 & -0.21 & -0.21 & -0.03 & -0.06 & -0.07 & 0.45 & 0.04 \\
\hline TSC1 & -0.05 & -0.26 & -0.08 & -0.35 & 0.11 & 0.04 & 0.02 & 0.00 & 0.04 & -0.10 & -0.10 & -0.02 & -0.03 & 0.04 & 0.33 & -0.01 \\
\hline TSS2 & -0.09 & -0.19 & -0.17 & -0.26 & 0.11 & 0.01 & -0.07 & -0.06 & 0.08 & -0.17 & -0.28 & -0.04 & -0.21 & -0.06 & 0.25 & -0.02 \\
\hline TSA2 & -0.21 & -0.31 & -0.27 & -0.36 & 0.16 & 0.03 & -0.08 & -0.06 & 0.10 & -0.24 & -0.35 & -0.03 & -0.21 & -0.14 & 0.37 & 0.01 \\
\hline TSC2 & -0.05 & -0.13 & -0.12 & -0.16 & 0.13 & 0.06 & -0.04 & -0.02 & 0.06 & -0.07 & -0.23 & 0.02 & -0.13 & -0.02 & 0.14 & 0.01 \\
\hline TSS3 & 0.06 & -0.02 & 0.09 & 0.00 & 0.03 & 0.03 & 0.09 & 0.02 & -0.12 & 0.01 & -0.05 & 0.02 & -0.02 & 0.14 & -0.01 & 0.02 \\
\hline TSA3 & -0.22 & -0.18 & -0.21 & -0.20 & 0.06 & 0.00 & 0.02 & 0.00 & -0.01 & -0.19 & -0.19 & -0.03 & -0.10 & -0.13 & 0.18 & 0.05 \\
\hline TSC3 & -0.21 & -0.15 & -0.24 & -0.22 & 0.01 & 0.00 & 0.01 & 0.01 & 0.02 & -0.24 & -0.23 & -0.11 & -0.14 & -0.09 & 0.21 & 0.03 \\
\hline
\end{tabular}


Table 1: Variable Correlation Matrix, cont'd.

\begin{tabular}{|c|c|c|c|c|c|c|c|c|c|c|c|c|c|c|c|c|}
\hline Variable & MINEDN & AXED I & MINK & MAXK & MINL & MAXL & ADJ & LANG & DIST & MINPOIV & AXPOIN & IINTL I & MINTL & IND & DEV & $\mathbf{C U}$ \\
\hline Factor Endowm & ents & & & & & & & & & & & & & & & \\
\hline MINED & 1 & 0.48 & 0.78 & 0.45 & -0.11 & 0.00 & 0.04 & 0.03 & 0.05 & 0.02 & 0.12 & -0.11 & -0.02 & 0.33 & -0.33 & -0.11 \\
\hline MAXED & 0.48 & 1 & 0.45 & 0.76 & -0.09 & 0.14 & -0.02 & -0.03 & 0.07 & 0.01 & 0.05 & -0.10 & 0.02 & 0.23 & -0.59 & -0.16 \\
\hline MINK & 0.78 & 0.45 & 1 & 0.49 & -0.11 & 0.06 & 0.07 & 0.00 & 0.08 & 0.00 & 0.07 & -0.08 & 0.01 & 0.39 & -0.35 & -0.10 \\
\hline MAXK & 0.45 & 0.76 & 0.49 & 1 & -0.06 & 0.11 & -0.03 & -0.11 & 0.12 & 0.05 & 0.07 & -0.03 & 0.03 & 0.22 & -0.71 & -0.21 \\
\hline MINL & -0.11 & -0.09 & -0.11 & -0.06 & 1 & 0.39 & 0.04 & 0.01 & -0.21 & 0.18 & 0.07 & 0.54 & 0.24 & 0.03 & -0.05 & 0.09 \\
\hline MAXL & 0.00 & 0.14 & 0.06 & 0.11 & 0.39 & 1[ & 0.00 & 0.04 & 0.01 & 0.11 & -0.02 & 0.31 & 0.41 & 0.09 & -0.14 & 0.07 \\
\hline Gravity variables & & & & & & & & & & & & & & & & \\
\hline ADJ & 0.04 & -0.02 & 0.07 & -0.03 & 0.04 & 0.00 & 1 & 0.07 & -0.19 & 0.06 & 0.03 & 0.06 & 0.03 & 0.13 & 0.02 & 0.09 \\
\hline LANG & 0.03 & -0.03 & 0.00 & -0.11 & 0.01 & 0.04 & 0.07 & 1 & -0.16 & -0.03 & -0.04 & -0.02 & 0.00 & -0.01 & 0.05 & 0.21 \\
\hline DIST & 0.05 & 0.07 & 0.08 & 0.12 & -0.21 & 0.01 & -0.19 & -0.16 & 1 & -0.02 & 0.08 & -0.05 & 0.08 & -0.12 & 0.04 & -0.17 \\
\hline MINPOP & 0.02 & 0.01 & 0.00 & 0.05 & 0.18 & 0.11 & 0.06 & -0.03 & -0.02 & 1 & 0.44 & 0.63 & 0.37 & 0.09 & -0.13 & -0.06 \\
\hline MAXPOP & 0.12 & 0.05 & 0.07 & 0.07 & 0.07 & -0.02 & 0.03 & -0.04 & 0.08 & 0.44 & 1 & 0.36 & 0.60 & 0.07 & -0.12 & -0.12 \\
\hline MINTL & -0.11 & -0.10 & -0.08 & -0.03 & 0.54 & 0.31 & 0.06 & -0.02 & -0.05 & 0.63 & 0.36 & 1 & 0.44 & 0.06 & -0.09 & 0.02 \\
\hline MAXTL & -0.02 & 0.02 & 0.01 & 0.03 & 0.24 & 0.41 & 0.03 & 0.00 & 0.08 & 0.37 & 0.60 & 0.44 & 1 & 0.02 & -0.04 & -0.01 \\
\hline IND & 0.33 & 0.23 & 0.39 & 0.22 & 0.03 & 0.09 & 0.13 & -0.01 & -0.12 & 0.09 & 0.07 & 0.06 & 0.02 & 1 & -0.27 & -0.02 \\
\hline DEV & -0.33 & -0.59 & -0.35 & -0.71 & -0.05 & -0.14 & 0.02 & 0.05 & 0.04 & -0.13 & -0.12 & -0.09 & -0.04 & -0.27 & 1 & 0.09 \\
\hline nion & & & & & & & & & & & & & & & & \\
\hline $\mathbf{C U}$ & -0.11 & -0.16 & -0.10 & -0.21 & 0.09 & 0.07 & 0.09 & 0.21 & -0.17 & -0.06 & -0.12 & 0.02 & -0.01 & -0.02 & 0.09 & \\
\hline
\end{tabular}


Table 2: Regression of business-cycle correlation on gravity variables A. Without country fixed effects

\begin{tabular}{lrrrr}
\hline Independent variables & \multicolumn{1}{c}{$\boldsymbol{\beta}$} & Std. Error & \multicolumn{1}{c}{ t } & pr $>|\mathbf{t}|$ \\
\hline constant & 0.045 & 0.042 & 2.07 & 0.2853 \\
Adjacency & 0.131 & 0.027 & 4.77 & $<.0001$ \\
Common Language & 0.014 & 0.009 & 1.52 & 0.1289 \\
Distance & $-1.2 \mathrm{E}-6$ & $7.5 \mathrm{E}-07$ & -1.59 & 0.1111 \\
Minimum log(Population) & 0.005 & 0.003 & 1.66 & 0.0967 \\
Maximum log(Population) & -0.003 & 0.003 & -1.12 & 0.2622 \\
Minimum log(Total land area) & -0.006 & 0.002 & -2.82 & 0.0049 \\
Maximum log(Total land area) & 0.006 & 0.003 & 2.07 & 0.0383 \\
Two industrialized countries & 0.284 & 0.017 & 16.85 & $<.0001$ \\
Two developing countries & -0.040 & 0.007 & -5.86 & $<.0001$
\end{tabular}

Adjusted R-Square: 0.076

Number of observations: 5670 country pairs

\section{B. With country fixed effects}

\begin{tabular}{lrrrr}
\hline Independent variables & $\boldsymbol{\beta}$ & Std. Error & \multicolumn{1}{c}{ t } & pr $>|\mathbf{t}|$ \\
\hline Adjacency & 0.121 & 0.026 & 4.59 & 0.00 \\
Common Language & 0.017 & 0.009 & 1.79 & 0.07 \\
Distance & $-3.3 \mathrm{E}-06$ & $9.2 \mathrm{E}-07$ & -3.61 & 0.00 \\
Minimum log(Population) & -0.011 & 0.007 & -1.63 & 0.10 \\
Minimum log(Total land area) & -0.002 & 0.005 & -0.42 & 0.68 \\
Two industrialized countries & 0.240 & 0.019 & 12.85 & 0.00
\end{tabular}

Adjusted R-Square: 0.2113 
Table 3

Extreme Bounds Analysis of Bilateral Trade Dependent Variable: Bilateral Correlation of Cyclic Output

\begin{tabular}{|c|c|c|c|c|c|c|c|c|}
\hline M-Var & & \multicolumn{3}{|c|}{ Std. } & R-sq & \multicolumn{2}{|c|}{ Z-Variables } & $\begin{array}{l}\text { Robust/ } \\
\text { Fragile }\end{array}$ \\
\hline \multicolumn{9}{|c|}{ Robustness Tests with No "Always-Included" Variables } \\
\hline \multirow[t]{3}{*}{ BT1 } & High & 2.82 & 0.28 & 10.00 & $0.19 \mathrm{CU}$ & MAXPOP & MINTL & robust \\
\hline & Base & 2.42 & 0.26 & 9.34 & 0.20 & & & \\
\hline & Low & 1.42 & 0.38 & 3.70 & 0.21 ISA1 & ADJ & DEV & \\
\hline \multirow[t]{3}{*}{ BT2 } & High & 11.89 & 1.93 & 6.16 & 0.18 ISC1 & MAXL & MINPOP & robust \\
\hline & Base & 9.27 & 1.04 & 8.90 & 0.20 & & & \\
\hline & Low & 5.64 & 1.62 & 3.48 & 0.20 ISA1 & ADJ & DEV & \\
\hline \multirow[t]{3}{*}{ BT3 } & High & 2.85 & 0.31 & 9.17 & $0.19 \mathrm{CB}$ & ADJ & MINPOP & robust \\
\hline & Base & 3.13 & 0.28 & 11.14 & 0.19 & & & \\
\hline & Low & 1.31 & 0.32 & 4.13 & 0.41 TSA3 & DIST & IND & \\
\hline \multirow[t]{3}{*}{ BT4 } & High & 5.47 & 0.86 & 6.39 & 0.16 ISC1 & MAXL & MINPOP & robust \\
\hline & Base & 5.07 & 0.47 & 10.76 & 0.19 & & & \\
\hline & Low & 2.67 & 0.75 & 3.56 & 0.38 ISA1 & TSA3 & DIST & \\
\hline \multicolumn{9}{|c|}{ Robustness Tests with Gravity Variables Always Included } \\
\hline \multirow[t]{3}{*}{ BT1 } & High & 1.21 & 0.39 & 3.10 & 0.21 ISC1 & MAXK & $\mathrm{CU}$ & robust \\
\hline & Base & 1.34 & 0.32 & 4.24 & 0.22 & & & \\
\hline & Low & 0.67 & 0.40 & 1.67 & 0.31 ISA1 & TSA1 & MAXED & \\
\hline \multirow[t]{3}{*}{ BT2 } & High & 4.84 & 2.23 & 2.17 & 0.20 ISC1 & MAXL & $\mathrm{CU}$ & fragile \\
\hline & Base & 4.57 & 1.19 & 3.84 & 0.22 & & & \\
\hline & Low & 2.69 & 2.25 & 1.20 & 0.27 ISA1 & TSA1 & MAXL & \\
\hline \multirow[t]{3}{*}{ ВT3 } & High & 1.65 & 0.44 & 3.77 & 0.20 ISC1 & MAXK & $\mathrm{CU}$ & fragile \\
\hline & Base & 1.48 & 0.33 & 4.45 & 0.20 & & & \\
\hline & Low & 0.57 & 0.48 & 1.18 & $0.40 \mathrm{TT} 2$ & ISA1 & TSA3 & \\
\hline \multirow[t]{3}{*}{ BT4 } & High & 2.65 & 0.95 & 2.79 & 0.18 ISC1 & MAXK & MINL & fragile \\
\hline & Base & 2.46 & 0.53 & 4.62 & 0.20 & & & \\
\hline & Low & 0.94 & 1.04 & 0.91 & 0.38 ISA1 & TSA3 & MINL & \\
\hline
\end{tabular}


Table 4

Extreme Bounds Analysis of Total Trade

Dependent Variable: Bilateral Correlation of Cyclic Output

\begin{tabular}{|c|c|c|c|c|c|c|c|c|c|}
\hline M-Var & \multicolumn{4}{|c|}{ Std. } & R-sq & \multicolumn{3}{|c|}{ Z-Variables } & $\begin{array}{l}\text { Robust/ } \\
\text { Fragile }\end{array}$ \\
\hline \multicolumn{10}{|c|}{ Robustness Tests with No "Always-Included" Variables } \\
\hline \multirow[t]{3}{*}{ TT1 } & High & 0.02 & 0.08 & 0.28 & 0.24 & ISC1 & ISC2 & MAXPOP & fragile \\
\hline & Base & -0.26 & 0.05 & -5.48 & 0.19 & & & & \\
\hline & Low & -0.46 & 0.09 & -5.22 & 0.37 & TSA3 & MINPOP & MAXTL & \\
\hline \multirow[t]{3}{*}{ TT2 } & High & -0.01 & 0.03 & -0.44 & 0.42 & ISC1 & ISC2 & TSC3 & fragile \\
\hline & Base & -0.14 & 0.02 & -8.07 & 0.18 & & & & \\
\hline & Low & -0.16 & 0.03 & -5.54 & 0.36 & TSA3 & MINPOP & MINTL & \\
\hline \multicolumn{10}{|c|}{ Robustness Tests with Gravity Variables Always Included } \\
\hline \multirow[t]{3}{*}{ TT1 } & High & 0.06 & 0.08 & 0.79 & 0.27 & BT2 & ISC1 & ISC2 & fragile \\
\hline & Base & -0.14 & 0.05 & -2.61 & 0.22 & & & & \\
\hline & Low & -0.32 & 0.12 & -2.68 & 0.40 & ISC1 & TSC3 & MINL & \\
\hline \multirow[t]{3}{*}{ TT2 } & High & -0.03 & 0.04 & -0.64 & 0.44 & ISS1 & ISS2 & TSS3 & fragile \\
\hline & Base & -0.08 & 0.02 & -4.32 & 0.20 & & & & \\
\hline & Low & -0.11 & 0.04 & -2.70 & 0.39 & ISS1 & TSS3 & MINL & \\
\hline
\end{tabular}


Table 5

Extreme Bounds Analysis of Industrial Structure

Dependent Variable: Bilateral Correlation of Cyclic Output

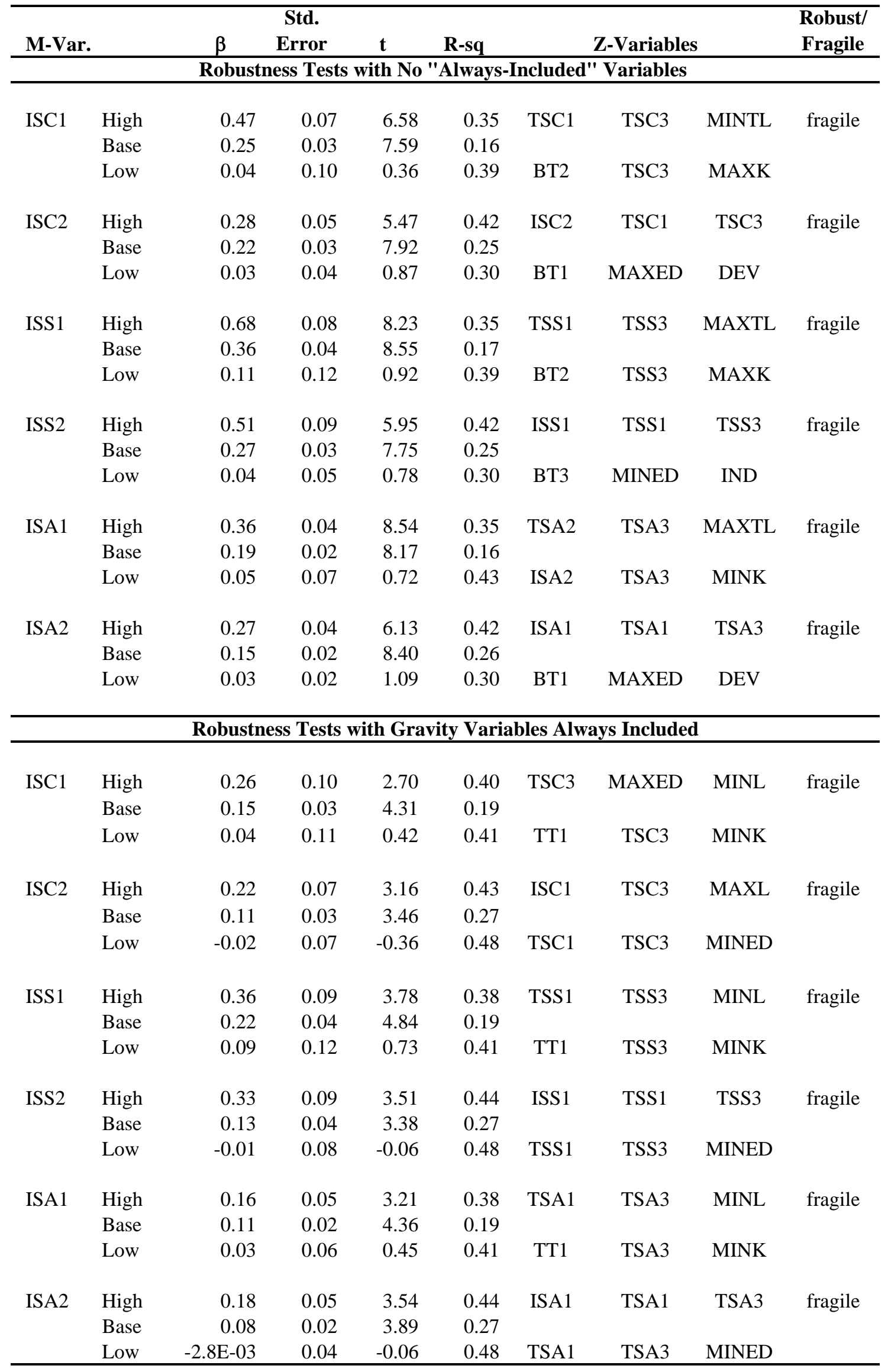


Table 6

Extreme Bounds Analysis of Structure of Bilateral Trade

Dependent Variable: Bilateral Correlation of Cyclic Output

\begin{tabular}{|c|c|c|c|c|c|c|c|c|c|}
\hline \multicolumn{2}{|c|}{ M-Var. } & \multicolumn{3}{|c|}{ Std. } & R-sq & & Z-Variables & & \multirow[t]{2}{*}{$\begin{array}{c}\text { Robust/ } \\
\text { Fragile }\end{array}$} \\
\hline \multicolumn{9}{|c|}{ Robustness Tests with No "Always-Included" Variables } & \\
\hline \multirow[t]{3}{*}{ TSC1 } & High & 0.16 & 0.03 & 6.31 & 0.38 & TSC3 & MAXED & MINPOP & fragile \\
\hline & Base & 0.06 & 0.01 & 4.72 & 0.26 & & & & \\
\hline & Low & 0.00 & 0.04 & 0.02 & 0.42 & ISC1 & ISC2 & TSC3 & \\
\hline \multirow[t]{3}{*}{ TSC2 } & High & 0.16 & 0.06 & 2.71 & 0.39 & TSC3 & MAXED & DIST & fragile \\
\hline & Base & 0.03 & 0.03 & 0.96 & 0.26 & & & & \\
\hline & Low & -0.06 & 0.08 & -0.81 & 0.42 & ISC1 & ISC2 & TSC3 & \\
\hline \multirow[t]{5}{*}{ TSC3 } & High & 0.06 & 0.02 & 3.48 & 0.39 & MAXED & LANG & DIST & fragile \\
\hline & Base & 0.02 & 0.02 & 1.58 & 0.35 & & & & \\
\hline & Low & -0.04 & 0.02 & -1.83 & 0.38 & ВT2 & ISC1 & TSC1 & \\
\hline & Base & 0.08 & 0.02 & 4.54 & 0.26 & & & & \\
\hline & Low & -0.07 & 0.05 & -1.37 & 0.42 & ISS1 & ISS2 & TSS3 & \\
\hline \multirow[t]{3}{*}{ TSS2 } & High & 0.32 & 0.10 & 3.31 & 0.39 & TSS3 & MAXED & DIST & fragile \\
\hline & Base & 0.07 & 0.06 & 1.16 & 0.26 & & & & \\
\hline & Low & -0.26 & 0.13 & -2.02 & 0.43 & ISS1 & ISS2 & TSS3 & \\
\hline \multirow[t]{3}{*}{ TSS3 } & High & 0.04 & 0.02 & 2.11 & 0.36 & MAXED & MAXPOP & MAXTL & fragile \\
\hline & Base & 0.04 & 0.02 & 2.10 & 0.35 & & & & \\
\hline & Low & -0.06 & 0.03 & -1.96 & 0.44 & ВТ2 & ISS1 & ISS2 & \\
\hline \multirow[t]{3}{*}{ TSA1 } & High & 0.12 & 0.02 & 5.80 & 0.38 & TSA2 & TSA3 & MAXED & fragile \\
\hline & Base & 0.05 & 0.01 & 5.36 & 0.26 & & & & \\
\hline & Low & -0.02 & 0.02 & -1.02 & 0.42 & ISA1 & ISA2 & TSA3 & \\
\hline \multirow[t]{3}{*}{ TSA2 } & High & 0.15 & 0.04 & 3.76 & 0.39 & TSA3 & MF1 & DIST & fragile \\
\hline & Base & 0.02 & 0.02 & 0.79 & 0.26 & & & & \\
\hline & Low & -0.10 & 0.05 & -1.78 & 0.42 & ISA1 & ISA2 & TSA3 & \\
\hline \multirow[t]{3}{*}{ TSA3 } & High & 0.05 & 0.01 & 3.65 & 0.39 & MAXED & LANG & DIST & fragile \\
\hline & Base & 0.02 & 0.01 & 1.26 & 0.35 & & & & \\
\hline & Low & -0.02 & 0.02 & -1.37 & 0.43 & BT4 & ISA1 & MISA3 & \\
\hline
\end{tabular}


Table 6, cont'd.

Extreme Bounds Analysis of Structure of Bilateral Trade

Dependent Variable: Bilateral Correlation of Cyclic Output

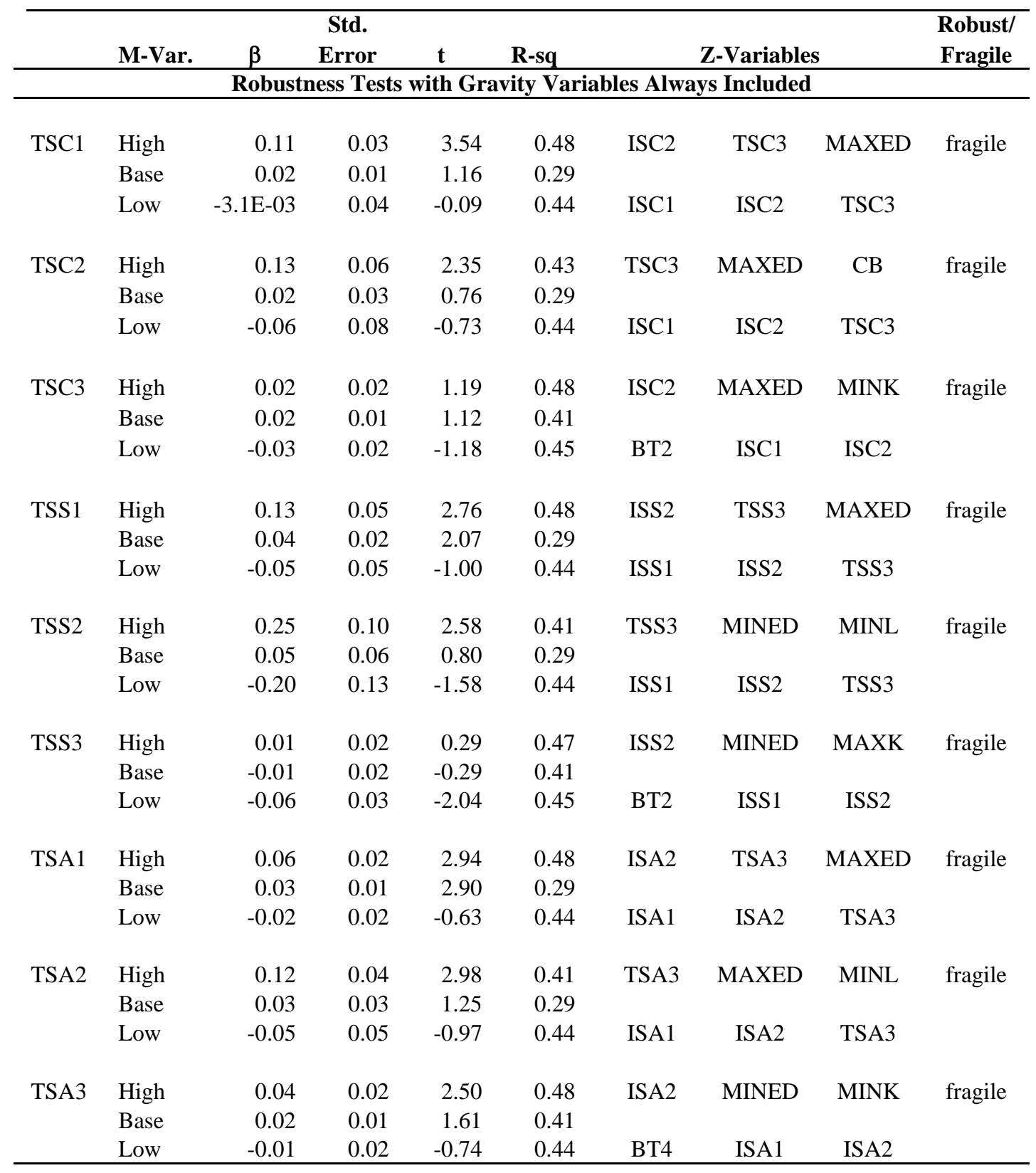


Table 7

Extreme Bounds Analysis of Factor EndowmentVariables

Dependent Variable: Bilateral Correlation of Cyclic Output

\begin{tabular}{|c|c|c|c|c|c|c|c|c|c|}
\hline M-Var. & & $\beta$ & \multicolumn{2}{|l|}{ Std. } & R-sq & \multicolumn{3}{|c|}{ Z-Variables } & \multirow[t]{2}{*}{$\begin{array}{c}\text { Robust/ } \\
\text { Fragile } \\
\end{array}$} \\
\hline \multicolumn{9}{|c|}{ Robustness Tests with No "Always-Included" Variables } & \\
\hline \multirow[t]{3}{*}{ MINED } & High & 0.21 & 0.06 & 3.30 & 0.38 & TT1 & ISC1 & TSC3 & fragile \\
\hline & Base & 0.12 & 0.02 & 6.27 & 0.20 & & & & \\
\hline & Low & -0.14 & 0.06 & -2.56 & 0.45 & ISC2 & TSC3 & MAXK & \\
\hline \multirow[t]{3}{*}{ MAXED } & High & 0.14 & 0.06 & 2.56 & 0.45 & ISC2 & TSC3 & MINK & fragile \\
\hline & Base & -0.12 & 0.02 & -6.27 & 0.20 & & & & \\
\hline & Low & -0.21 & 0.06 & -3.30 & 0.38 & TT1 & ISC1 & TSC3 & \\
\hline \multirow{3}{*}{ MINK } & High & 0.14 & 0.01 & 9.38 & 0.39 & TSA3 & MAXED & $\mathrm{CU}$ & fragile \\
\hline & Base & 0.05 & 0.01 & 10.00 & 0.18 & & & & \\
\hline & Low & 0.02 & 0.01 & 1.33 & 0.21 & ISS1 & MINED & $\mathrm{DEV}$ & \\
\hline \multirow[t]{3}{*}{ MAXK } & High & -0.02 & 0.01 & -1.33 & 0.21 & ISS1 & MAXED & $\mathrm{DEV}$ & fragile \\
\hline & Base & -0.05 & 0.01 & -10.00 & 0.18 & & & & \\
\hline & Low & -0.14 & 0.01 & -9.38 & 0.39 & TSA3 & MINED & CU & \\
\hline \multirow[t]{3}{*}{ MINL } & High & 0.05 & 0.02 & 3.33 & 0.41 & TT1 & ISC2 & TSC3 & fragile \\
\hline & Base & 0.02 & 0.01 & 1.73 & 0.15 & & & & \\
\hline & Low & 0.00 & 0.02 & 0.17 & 0.37 & BT4 & TSS3 & MINED & \\
\hline \multirow[t]{3}{*}{ MAXL } & High & 0.00 & 0.02 & -0.17 & 0.37 & BT4 & TSS3 & MAXED & fragile \\
\hline & Base & -0.02 & 0.01 & -1.73 & 0.15 & & & & \\
\hline & Low & -0.05 & 0.02 & -3.33 & 0.41 & TT1 & ISC2 & TSC3 & \\
\hline \multicolumn{10}{|c|}{ Robustness Tests with Gravity Variables Always Included } \\
\hline \multirow[t]{3}{*}{ MINED } & High & 0.05 & 0.07 & 0.73 & 0.42 & BT2 & ISA1 & TSA3 & fragile \\
\hline & Base & 0.03 & 0.02 & 1.64 & 0.24 & & & & \\
\hline & Low & -0.13 & 0.06 & -2.39 & 0.48 & ISC2 & TSC3 & MAXK & \\
\hline \multirow[t]{3}{*}{ MAXED } & High & 0.13 & 0.06 & 2.39 & 0.48 & ISC2 & TSC3 & MAXK & fragile \\
\hline & Base & -0.03 & 0.02 & -1.64 & 0.24 & & & & \\
\hline & Low & -0.05 & 0.07 & -0.73 & 0.42 & BT2 & ISA1 & TSA3 & \\
\hline \multirow[t]{3}{*}{ MINK } & High & 0.06 & 0.03 & 2.05 & 0.44 & ISC1 & ISC2 & TSC3 & fragile \\
\hline & Base & 0.02 & 0.01 & 2.91 & 0.20 & & & & \\
\hline & Low & $-1.2 \mathrm{E}-03$ & 0.02 & -0.08 & 0.23 & TT1 & ISA1 & MINED & \\
\hline \multirow[t]{3}{*}{ MAXK } & High & 0.00 & 0.02 & 0.08 & 0.23 & TT1 & ISA1 & MAXED & fragile \\
\hline & Base & -0.02 & 0.01 & -2.91 & 0.20 & & & & \\
\hline & Low & -0.06 & 0.03 & -2.05 & 0.44 & ISC1 & ISC2 & TSC3 & \\
\hline \multirow[t]{3}{*}{ MINL } & High & 0.04 & 0.02 & 1.92 & 0.43 & ISC1 & ISC2 & TSC3 & fragile \\
\hline & Base & 0.01 & 0.01 & 1.24 & 0.19 & & & & \\
\hline & Low & 2.8E-03 & 0.02 & 0.18 & 0.41 & BT4 & TSS3 & MAXED & \\
\hline \multirow[t]{3}{*}{ MAXL } & High & $-2.8 \mathrm{E}-03$ & 0.02 & -0.18 & 0.41 & BT4 & TSS3 & MAXED & fragile \\
\hline & Base & -0.01 & 0.01 & -1.24 & 0.19 & & & & \\
\hline & Low & -0.04 & 0.02 & -1.92 & 0.43 & ISC1 & ISC2 & TSC3 & \\
\hline
\end{tabular}


Table 8

Extreme Bounds Analysis of Currency Union/Currency Board

Dependent Variable: Bilateral Correlation of Cyclic Output

\begin{tabular}{|c|c|c|c|c|c|c|c|c|c|}
\hline \multicolumn{2}{|c|}{ M-Var. } & \multicolumn{3}{|c|}{ Std. } & R-sq & \multicolumn{3}{|c|}{ Z-Variables } & \multirow[t]{2}{*}{$\begin{array}{l}\text { Robust } \\
\text { Fragile }\end{array}$} \\
\hline \multicolumn{9}{|c|}{ Robustness Tests with No "Always-Included" Variables } & \\
\hline \multirow[t]{3}{*}{$\mathrm{CU}$} & High & 0.32 & 0.07 & 4.45 & 0.37 & ISC1 & TSC3 & ADJ & \multirow[t]{3}{*}{ fragile } \\
\hline & Base & 0.08 & 0.03 & 2.90 & 0.17 & & & & \\
\hline & Low & -0.20 & 0.12 & -1.77 & 0.20 & TT1 & ISA1 & MINED & \\
\hline \multicolumn{10}{|c|}{ Robustness Tests with Gravity Variables Always Included } \\
\hline \multirow[t]{3}{*}{$\mathrm{CU}$} & High & 0.32 & 0.08 & 4.17 & 0.45 & ISC1 & ISC2 & TSC3 & \multirow[t]{3}{*}{ fragile } \\
\hline & Base & 0.03 & 0.03 & 1.13 & 0.20 & & & & \\
\hline & Low & -0.21 & 0.11 & -1.82 & 0.23 & TT1 & ISA1 & MINED & \\
\hline
\end{tabular}


Table 9

Extreme Bounds Analysis of Structure of Gravity Variables

Dependent Variable: Bilateral Correlation of Cyclic Output

\begin{tabular}{|c|c|c|c|c|c|c|c|c|c|}
\hline M-Var. & & $\beta$ & $\begin{array}{c}\text { Std. } \\
\text { Error }\end{array}$ & $\mathbf{t}$ & R-sq & & Z-Variable & & \multirow[t]{2}{*}{$\begin{array}{c}\text { Robust/ } \\
\text { Fragile }\end{array}$} \\
\hline \multicolumn{9}{|c|}{ Robustness Tests with No "Always-Included" Variables } & \\
\hline \multirow[t]{3}{*}{ DIST } & High & $-2.3 \mathrm{E}-06$ & 1.1E-06 & -2.03 & 0.28 & ВТ3 & ISC2 & MAXK & robust \\
\hline & Base & $-5.9 \mathrm{E}-06$ & 8.6E-07 & -6.87 & 0.17 & & & & \\
\hline & Low & $-1.3 \mathrm{E}-05$ & $1.4 \mathrm{E}-06$ & -9.24 & 0.37 & TSA2 & TSA3 & MINTL & \\
\hline \multirow[t]{3}{*}{ ADJ } & High & 0.23 & 0.03 & 7.58 & 0.37 & TSA1 & TSA3 & MAXPOP & fragile \\
\hline & Base & 0.19 & 0.03 & 7.36 & 0.17 & & & & \\
\hline & Low & 0.05 & 0.05 & 1.02 & 0.26 & BT2 & ISA1 & ISA2 & \\
\hline \multirow[t]{3}{*}{ LANG } & High & 0.07 & 0.02 & 4.15 & 0.36 & ISC1 & TSC3 & MAXTL & fragile \\
\hline & Base & 0.03 & 0.01 & 3.58 & 0.17 & & & & \\
\hline & Low & -0.01 & 0.01 & -0.58 & 0.29 & BT2 & ISA2 & DIST & \\
\hline \multirow[t]{3}{*}{ MINPOP } & High & 0.05 & 0.02 & 2.94 & 0.37 & TT1 & ISC1 & TSC3 & fragile \\
\hline & Base & -0.01 & 0.01 & -1.15 & 0.17 & & & & \\
\hline & Low & -0.04 & 0.01 & -2.79 & 0.35 & TSC3 & MINGDP & MINTL & \\
\hline \multirow[t]{3}{*}{ MAXPOP } & High & 0.04 & 0.01 & 2.79 & 0.35 & TSC3 & MAXGDP & MAXTL & fragile \\
\hline & Base & 0.01 & 0.01 & 1.15 & 0.17 & & & & \\
\hline & Low & -0.05 & 0.02 & -2.94 & 0.37 & TT1 & ISC1 & TSC3 & \\
\hline \multirow[t]{3}{*}{ MINTL } & High & 0.02 & 0.01 & 1.87 & 0.36 & TT1 & ISC1 & TSC3 & fragile \\
\hline & Base & $-3.5 \mathrm{E}-03$ & 0.01 & -0.68 & 0.16 & & & & \\
\hline & Low & -0.02 & 0.01 & -1.70 & 0.40 & ISA2 & TSA3 & MINL & \\
\hline \multirow[t]{3}{*}{ MAXTL } & High & 0.02 & 0.01 & 1.70 & 0.40 & ISA2 & TSA3 & MAXL & fragile \\
\hline & Base & 3.5E-03 & 0.01 & 0.68 & 0.16 & & & & \\
\hline & Low & -0.02 & 0.01 & -1.87 & 0.36 & TT1 & ISC1 & TSC3 & \\
\hline \multirow[t]{3}{*}{ IND } & High & 0.29 & 0.03 & 11.56 & 0.41 & TSS3 & MINED & MINGDP & robust \\
\hline & Base & 0.25 & 0.02 & 13.65 & 0.20 & & & & \\
\hline & Low & 0.10 & 0.04 & 2.75 & 0.43 & ISA1 & ISA2 & TSA3 & \\
\hline \multirow[t]{3}{*}{$\mathrm{DEV}$} & High & 0.29 & 0.03 & 11.56 & 0.41 & TSS3 & MINED & MAXGDP & robust \\
\hline & Base & 0.25 & 0.02 & 13.65 & 0.20 & & & & \\
\hline & Low & 0.10 & 0.04 & 2.75 & 0.43 & ISA1 & ISA2 & TSA3 & \\
\hline
\end{tabular}




\section{Figure 1: Bilateral Trade and Business Cycle Correlation}

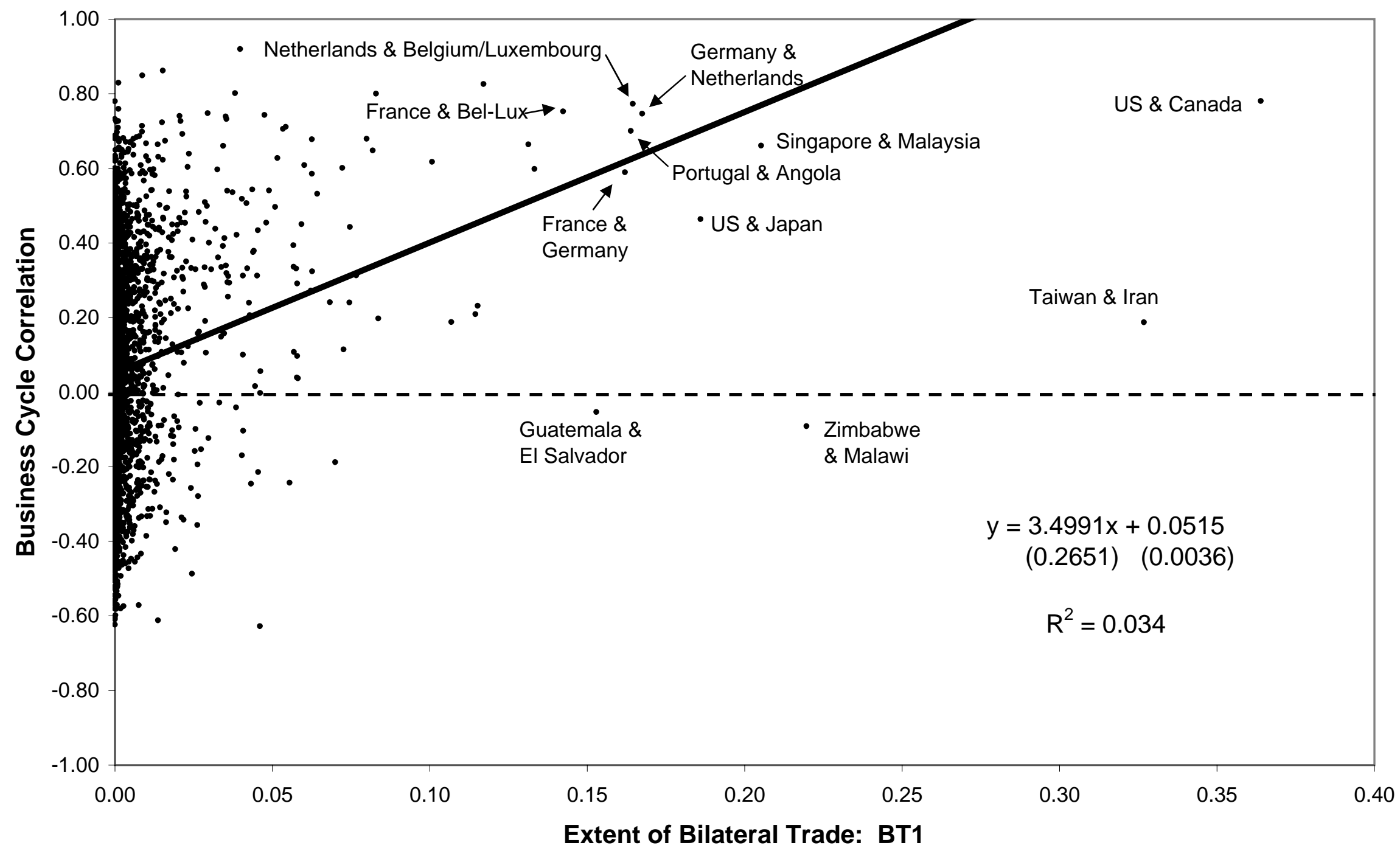


Figure 2: Total Trade and Business Cycle Correlation

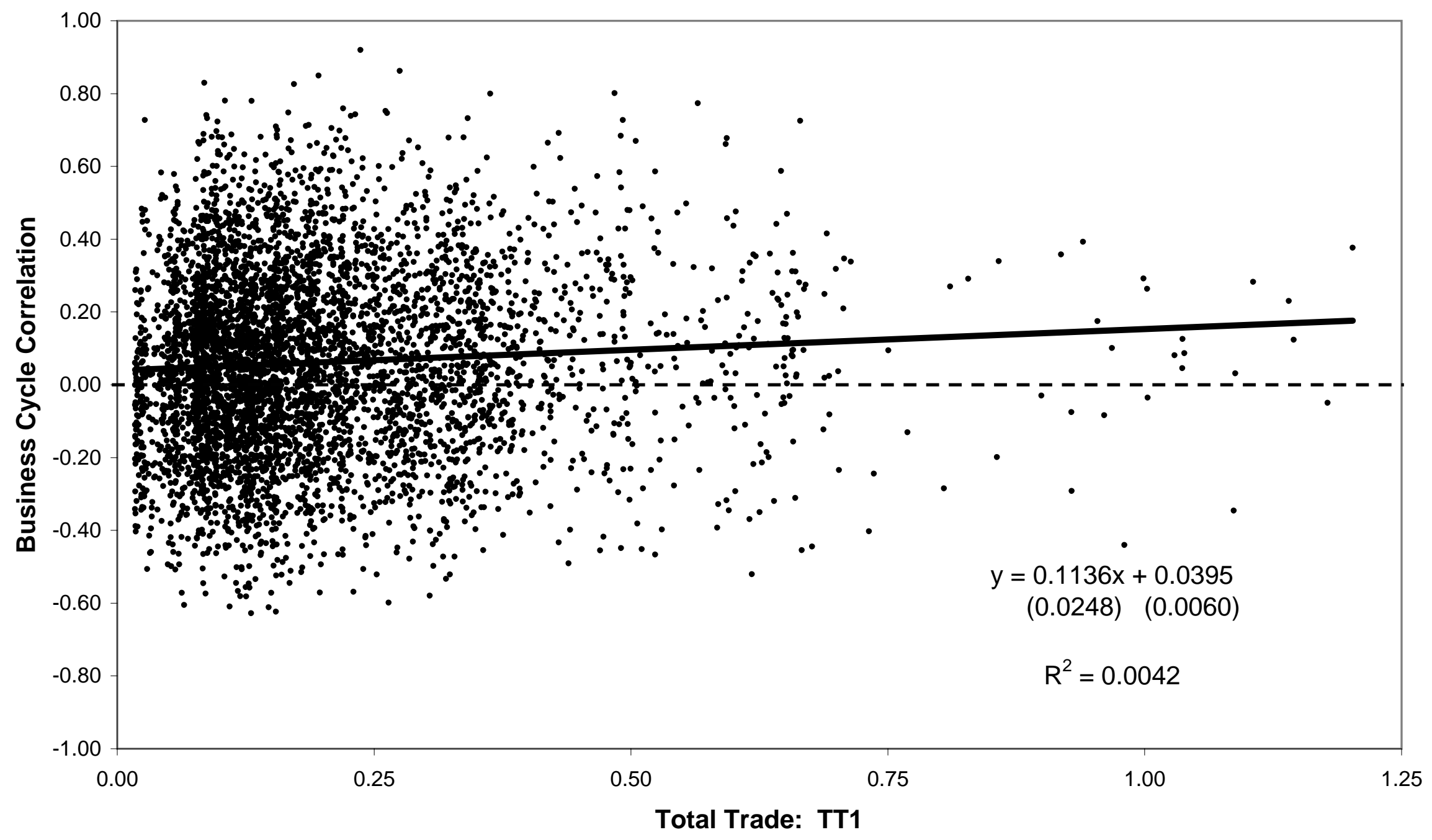


Figure 3: Industrial Similarity and Business Cycle Correlation

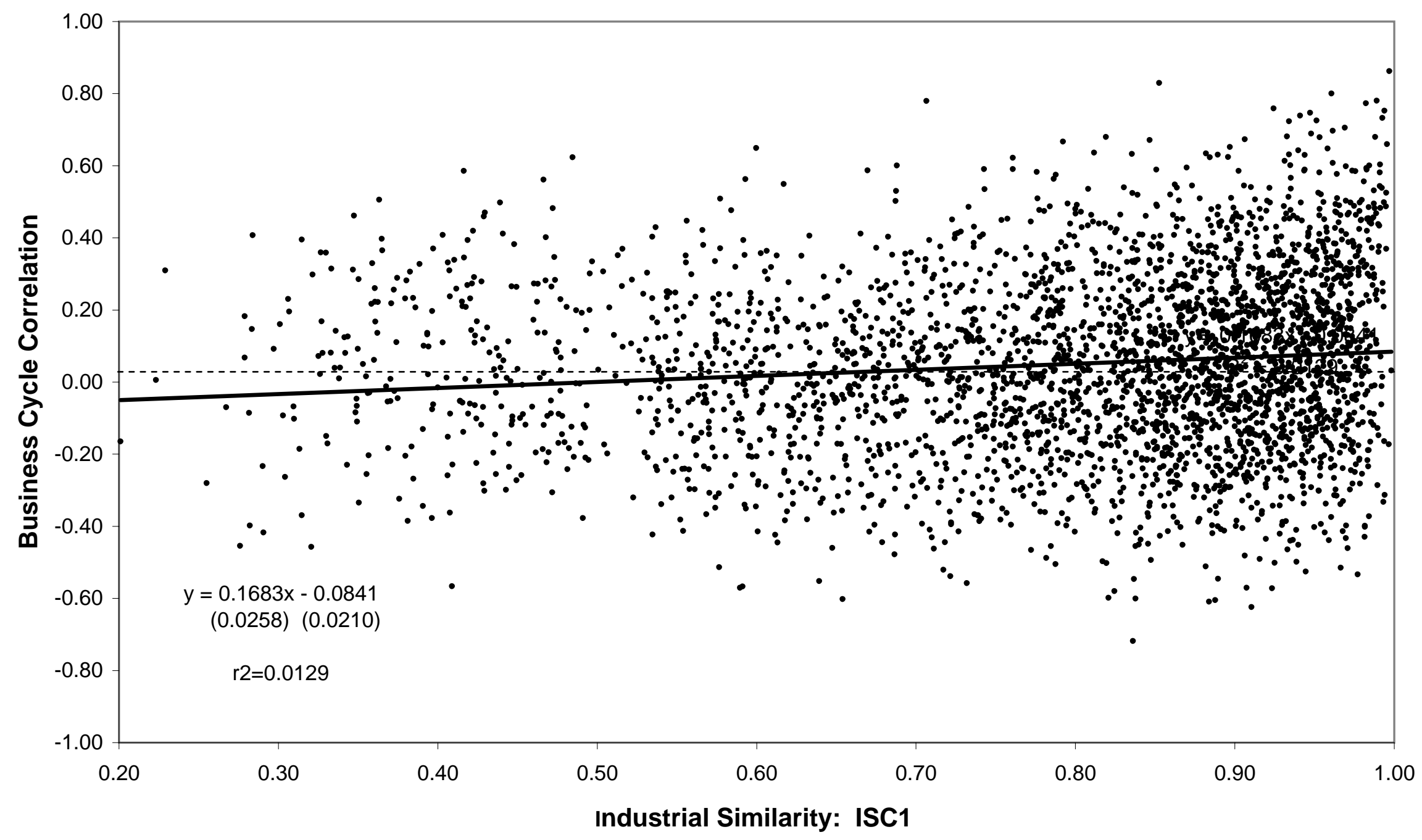


Figure 4: Similarity of Bilateral Trade and Business Cycle Correlation

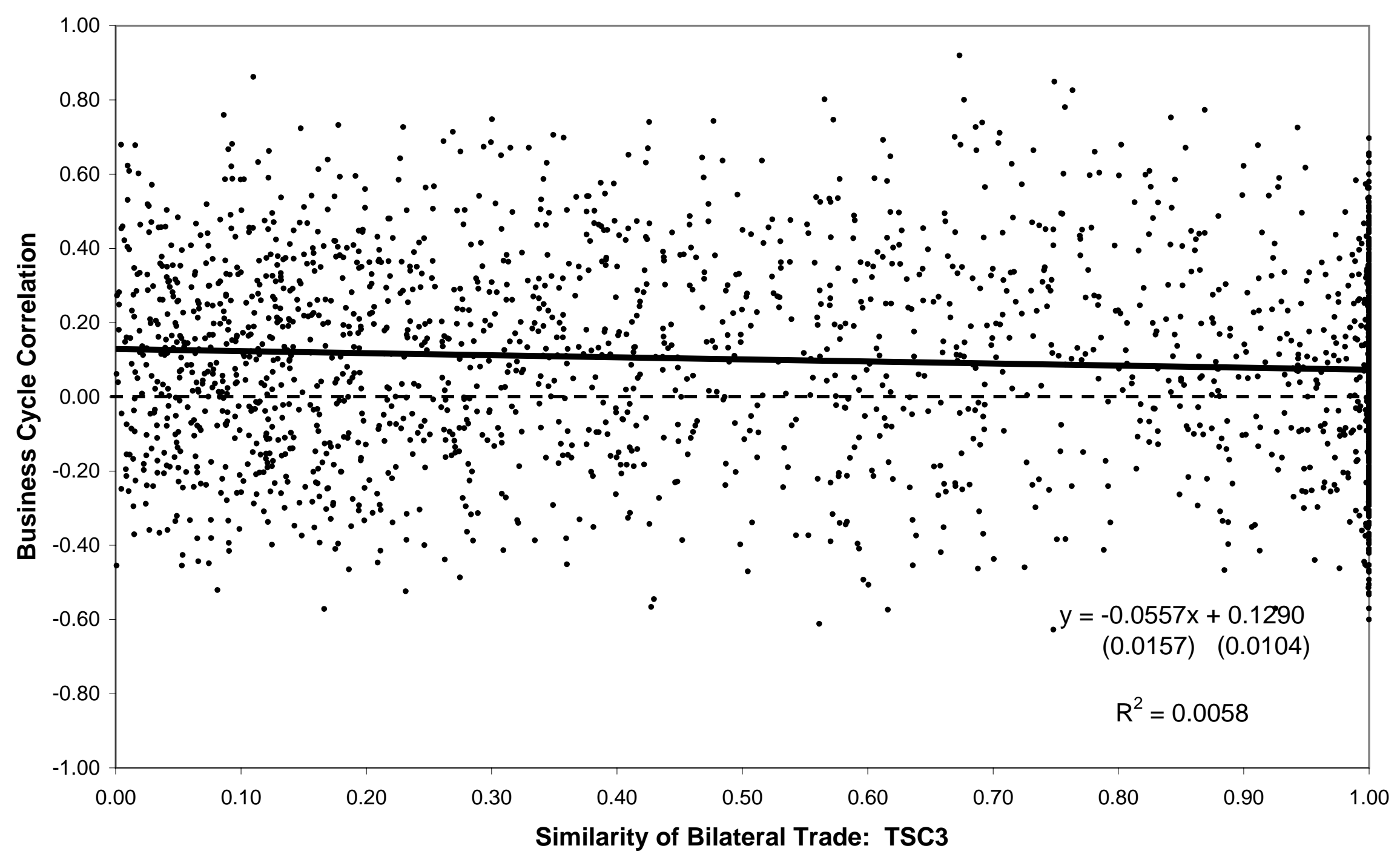


Figure 5: Minimum Education Level and Business Cycle Correlation

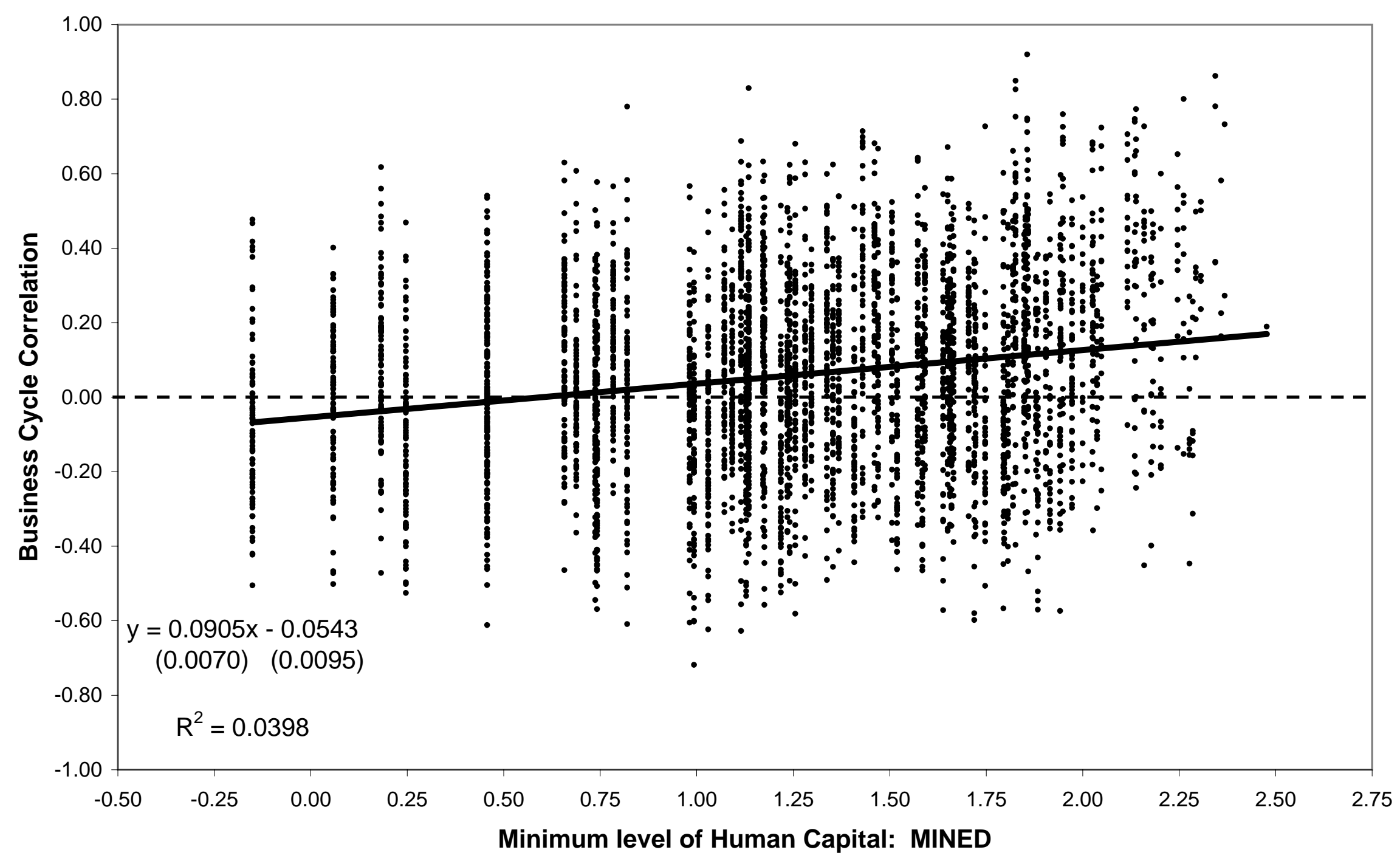


Figure 6: Distance and Business Cycle Correlation

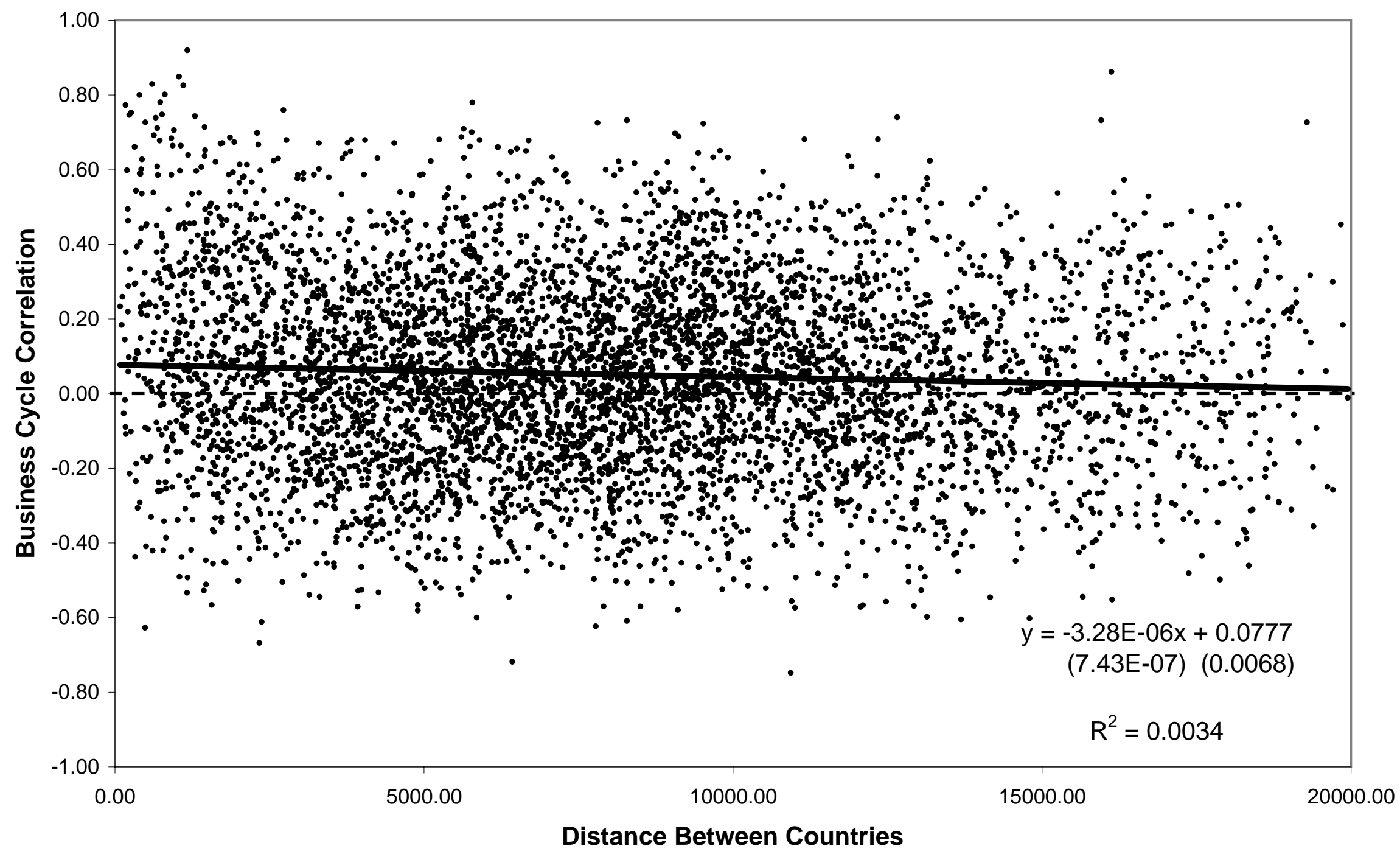

